\title{
U.S. Metropolitan House Price Dynamics
}

\author{
Elias Oikarinen ${ }^{*}$ \\ Department of Built Environment, Aalto University \\ PL 14100 \\ 00076 Aalto, Finland \\ and \\ School of Economics, University of Turku \\ Rehtorinpellonkatu 3 \\ 20500 Turku, Finland \\ elias.oikarinen@utu.fi \\ Steven C. Bourassa \\ School of Urban and Regional Planning \\ Florida Atlantic University \\ 777 Glades Road \\ Boca Raton, FL 33431 USA \\ sbourassa@fau.edu
Martin Hoesli
University of Geneva (GFRI and Swiss Finance Institute)
40 boulevard du Pont-d'Arve
CH-1211 Geneva 4, Switzerland
martin.hoesli@unige.ch

Also: University of Aberdeen Business School, U.K. and Kedge Business School, France

\author{
Janne Engblom \\ School of Economics, University of Turku \\ Rehtorinpellonkatu 3 \\ 20500 Turku, Finland \\ janne.engblom@utu.fi \\ * Corresponding author
}




\title{
U.S. Metropolitan House Price Dynamics
}

\begin{abstract}
Using data for 70 U.S. metropolitan areas, this study explores spatial heterogeneity in house price dynamics. We use recent advances in panel econometrics that allow for spatial heterogeneity, cross-sectional dependence, and non-stationary but cointegrated data. We test for spatial differences and analyze the relationship between the price elasticity of housing supply and the income elasticity of prices, as well as bubble size and duration. The long-term elasticity of house prices with respect to aggregate personal income averages 0.81 , but varies considerably across metropolitan areas. The long-term income elasticity generally is greater in the more supplyinelastic metropolitan areas, and we show that bubble size and duration are inversely related to supply elasticity. Also short-term momentum and reversion dynamics show substantial spatial heterogeneity.
\end{abstract}

Keywords: house prices, dynamics, panel data, spatial heterogeneity, spatial dependence, bubbles JEL codes: C33, R15, R31

\section{Introduction}

It is widely recognized that various panel tests, such as unit root and cointegration tests, have higher power than corresponding tests on individual time series or equations, and that panel estimations yield more efficient coefficient estimates. Therefore, a number of studies use panel data to investigate the housing market. Two common problems in these panel analyses of housing market dynamics are the implicit assumption of homogeneous dynamics across locations and the potential bias caused by cross-sectional (i.e., spatial) dependence in the data.

The assumption of spatial homogeneity is likely to be unrealistic, since urban economic theory and empirical evidence suggest that housing markets are local in nature and there can be considerable spatial differences in housing market dynamics. In particular, the elasticity of supply of housing - a key determinant of the dynamics - is shown to be determined largely by local factors that differ substantially across cities (Saiz, 2010; Paciorek, 2013). In addition, theoretical models and 
empirical evidence indicate spatial heterogeneity in the persistence of house price growth ("momentum") and in the adjustment speed of house prices towards their long-term fundamental levels (Lamont and Stein, 1999; Capozza et al., 2004; Glaeser et al., 2008).

Significant differences in house price dynamics across locations have several practical implications: (1) Predictions concerning the influences of nationwide policies that affect housing demand can be misleading if homogeneous dynamics are assumed within a country. (2) Local policy tools, too, can be suboptimal if based on average dynamics estimated across diverse housing markets. (3) The riskiness of metropolitan housing markets should be assessed taking into account spatial variations in dynamics. (4) House price predictions (and, by implication, metropolitan growth prospects) should also be based on local dynamics. This is relevant to the important role that housing plays in spatial equilibrium models (Glaeser et al., 2008; Glaeser and Gottlieb, 2009).

Since conventional panel data models that assume similar slope coefficients across space are likely to be too restrictive, some studies have allowed for spatial heterogeneity in house price dynamics. Abraham and Hendershott (1996), Lamont and Stein (1999), Capozza et al. (2004), and HarterDreiman (2004) all provide pioneering work that allows for at least some degree of heterogeneity. Abraham and Hendershott (1996) estimate separate models for house price dynamics in U.S. coastal and inland cities. Similarly, Harter-Dreiman (2004) estimates separate models for supplyconstrained and unconstrained cities, and for large and small cities. Lamont and Stein (1999) allow for variation in the coefficient on income change, but not in the other slope coefficients, in an equation for house price growth in U.S. cities. Capozza et al. (2004) let both the momentum effect and adjustment speed towards fundamental price levels differ across U.S. metropolitan areas, while not permitting heterogeneity in the long-term elasticities. These early studies generally ignore complications regarding the suitability of the estimators for non-stationary and cross-sectionally dependent data.

Anundsen and Heebøll (2014), Oikarinen and Engblom (2016), and Lai and Van Order (2017) represent more recent studies using panel models that allow for heterogeneity in slope coefficients. Anundsen and Heebøll (2014) explore differences across the largest 100 U.S. Metropolitan Statistical Areas (MSAs) using several methods, including the mean group and pooled mean group estimators of Pesaran and Smith (1995) and Pesaran et al. (1999). Oikarinen and Engblom (2016) investigate differences in price dynamics across Finnish cities. They estimate long-term dynamics separately for each city instead of relying on a panel estimator, but use fixed interaction effects to allow for different short-term parameter estimates across cities. Lai and Van Order (2017), who 
base their long-term price model on the Gordon dividend discount model, use the same mean group and pooled mean group estimators as Anundsen and Heebøll (2014) to study variation in the shorter-term momentum and reversion dynamics across 45 U.S. MSAs.

These three studies go beyond previous literature by formally testing for the significance of spatial differences. Based on the Hausman test, Lai and Van Order (2017) conclude that the long-run variables share the same parameters across MSAs. They also report notable variation in short-term dynamics between non-bubble and bubble MSAs, but do not test for the significance of this variation in a panel context. In contrast, Anundsen and Heebøll (2014) use a likelihood ratio test and conclude that there are significant differences in long- and short-term dynamics across U.S. MSAs. Oikarinen and Engblom (2016) argue that the overall likelihood ratio test statistics - which do not reject the hypothesis of homogeneity of short-term dynamics across cities - may be diluted, since for most cities the parameter estimates lie close to the mean value across cities, and show that in several cases an individual city-specific parameter estimate differs significantly from the mean.

The study by Holly et al. (2010) is the only one to date to take account of cross-sectional dependence, which they show can be an important issue in panel analyses of house price dynamics. ${ }^{1}$ They use the common correlated effects mean group (CCEMG) estimator of Pesaran (2006) that permits spatial heterogeneity in slope coefficients and asymptotically eliminates cross-sectional dependence in large panels. While allowing heterogeneity across U.S. states in long-term house price elasticity with respect to aggregate income and in short-term dynamics, Holly et al. (2010) concentrate on the estimation of average values of the coefficients rather than exploring the extent of spatial variation and its causes.

The aim of this study is to add to the scarce literature on spatial heterogeneity in house price dynamics using recent advances in panel econometrics. In contrast to Holly et al. (2010), we focus on analyzing spatial variation in dynamics. We investigate the extent of city-level differences in long-term income elasticity and in short-term dynamics using quarterly data for the 70 largest continental U.S. MSAs or MSA Divisions (MSADs) for the period 1980Q1 to 2015Q2. ${ }^{2}$ The analysis is a test of the validity of the conventional panel models that assume homogeneous dynamics across locations.

In addition to allowing for heterogeneous dynamics, the recent advances in panel econometrics also control for cross-sectional dependence in the data. Cross-sectional, or spatial, dependence is an

\footnotetext{
${ }^{1}$ Holly et al. (2011) also take account of cross-sectional dependence in a study of house price diffusion in the U.K.

${ }^{2}$ Subsequently, we use the abbreviation MSA to refer to both MSAs and MSADs.
} 
issue with respect to metropolitan house prices because equilibrium in a system of markets requires equalization of welfare across space (Glaeser and Gottlieb, 2009), and local welfare is a function of housing costs (and other factors). We apply several estimators that take account of cross-sectional dependence in the data: the augmented mean group (AMG) estimator of Eberhardt and Teal (2010), the CCEMG, and the dynamic CCEMG (DCCEMG) of Chudik and Pesaran (2015).

We contribute to the literature in several ways. First, no study before this concentrates on the extent of variation in both long- and short-term city-level house price dynamics applying a panel estimator that permits slope coefficients to be heterogeneous across locations and is consistent in the presence of cross-sectional dependence. Second, we are the first to test formally for the significance of spatial differences in both long-term and short-term price dynamics. Third, we analyze the differences across MSAs by relating the MSA-specific dynamics to supply restrictions and by investigating the deviations of house prices from long-term fundamental levels over time. Finally, this is the first study to apply the DCCEMG estimator - that is consistent in the presence of lagged dependent variables - to housing market dynamics.

We estimate the long-term elasticity of house prices with respect to aggregate personal income to average 0.81 across MSAs, but to vary considerably between cities. As expected, we find the MSAlevel long-term income elasticity to generally be inversely related to the elasticity of housing supply. Also, momentum and reversion dynamics show substantial spatial heterogeneity that can influence the duration and magnitude of house price cycles.

We show that house price cycles around long-term fundamental price levels generally are highly synchronized across MSAs within the same region, while there are substantially greater differences in the timing and magnitude of these cycles between more distant cities. The results also indicate that conventional panel estimators that do not consider cross-sectional dependence can yield overly large estimates for the house price momentum effect as well as inconsistent parameter signs.

Moreover, we provide evidence supporting the theoretical considerations of Glaeser et al. (2008) regarding both the size and the duration of price bubbles: the notable overvaluations relative to long-term fundamental price levels have occurred in relatively supply inelastic MSAs, and the duration of considerable overvaluations has generally been longer in the more supply-restricted MSAs. 
The next section presents a simple theoretical framework for our empirical analysis. Section three describes the data used in the empirical investigation, while section four discusses the empirical analysis, including robustness checks. The final section concludes the study.

\section{A simple theoretical framework}

The theoretical basis of our empirical analysis lies in a conventional housing market stock-flow model. Using the typical assumptions concerning housing demand and supply determinants in the stock-flow model we have:

$$
\begin{aligned}
& d_{i, t}{ }^{*}=\mathrm{f}\left(y_{i, t}, r_{i, t}, p_{i, t}\right)=\gamma_{0}+\gamma_{1} y_{i, t}-\gamma_{2} r_{i, t}-\gamma_{3} p_{i, t} \\
& s_{i, t}{ }^{*}=\mathrm{g}\left(p_{i, t}, c_{i, t}\right)=\phi_{0}+\phi_{1} p_{i, t}-\phi_{2} c_{i, t}
\end{aligned}
$$

In (1), the natural log of equilibrium demand for housing services $\left(d^{*}\right)$ in city $i$ and period $t$ is determined by the log of aggregate real income $(y)$ representing the purchasing power in the city, the real mortgage interest rate $(r)$ reflecting the opportunity cost of capital, and the log of house price level $(p)$. The parameter $\gamma_{l}$ represents the elasticity of housing demand with respect to aggregate income, $\gamma_{2}$ indicates the influence of the mortgage interest rate on housing demand, and $\gamma_{3}$ is the price elasticity of housing demand. The inverse of $\gamma_{3}$ gives the slope of the housing demand curve.

The steady-state level of log housing supply $\left(s^{*}\right)$, in turn, is a function of the log house price level and $\log$ construction costs $(c)$ in the city. In (2), $\phi_{1}$ reflects the long-term price elasticity of supply of housing and $\phi_{2}$ is the long-run supply elasticity with respect to construction costs. In the longterm (steady-state) market clearing equilibrium $d^{*}=s^{*}$. Using this equilibrium condition, we get:

$$
\gamma_{0}+\gamma_{1} y_{i, t}-\gamma_{2} r_{i, t}-\gamma_{3} p_{i, t}=\phi_{0}+\phi_{1} p_{i, t}-\phi_{2} c_{i, t}
$$

Based on (3), we can derive the reduced form equation for the long-term equilibrium house price level $\left(p^{*}\right)$ as a function of demand side factors and construction costs, as shown in (4). These three factors, $y, r$, and $c$, also are the key determinants of the long-term equilibrium for house prices in, for example, the DiPasquale and Wheaton (1992) four-quadrant model. In (4) and in the rest of the paper, we drop the subindex $i$ from $r$, since the mortgage rate is the same across the cities within our U.S. sample.

$$
p_{i, t}{ }^{*}=\mathrm{h}\left(d_{i, t}{ }^{*}, s_{i, t}{ }^{*}\right)=\beta_{0}+\beta_{1} y_{i, t}-\beta_{2} r_{t}+\beta_{3} c_{i, t}
$$


where

$$
\begin{aligned}
& \beta_{0}=\left(\gamma_{0}-\phi_{0}\right) /\left(\gamma_{3}+\phi_{1}\right) \\
& \beta_{1}=\gamma_{1} /\left(\gamma_{3}+\phi_{1}\right) \\
& \beta_{2}=\gamma_{2} /\left(\gamma_{3}+\phi_{1}\right) \\
& \beta_{3}=\phi_{2} /\left(\gamma_{3}+\phi_{1}\right)
\end{aligned}
$$

Note that "long-term" refers to a time period within which housing supply is able to fully adjust to changes in its determinants. In a frictionless and informationally efficient market, the adjustment to the new equilibrium would be instantaneous - prices and supply would react immediately to a shock so that (2) and (4) would hold in every period. In the housing market, however, the adjustment is typically highly sluggish due to the notable frictions such as construction lag, high transaction costs, imperfect and costly market information, and liquidity constraints. Because of the market frictions, the adjustment towards equilibrium in (4) is expected to be slow and the price level may deviate notably from $p^{*}$ in the short term even if market participants are fully rational (DiPasquale and Wheaton, 1994; Glaeser et al., 2014). In addition, behavioral factors such as feedback effects and loss aversion may affect short-term house price dynamics (e.g., DiPasquale and Wheaton, 1994; Genesove and Mayer, 2001; Dusansky and Koç, 2007; Røed Larsen and Weum, 2008). Taking account of these short-term features of housing market adjustment, urban house price movements can be presented in an error-correction form, where the current period price change is determined by the lagged price change, the lagged changes in market fundamentals, and by the previous period deviation of house price level from its long-term equilibrium level:

$$
\Delta p_{i, t}=\lambda_{0 i}+\lambda_{1} \Delta y_{i, t-1}-\lambda_{2} \Delta r_{t-1}+\lambda_{3} \Delta c_{i, t-1}+\lambda_{4} \Delta p_{i, t-1}-\lambda_{5}\left(p-p^{*}\right)_{i, t-1}+\varepsilon_{i, t}
$$

The kind of specification shown in (5) is typical in empirical examinations of house price dynamics (e.g., Lamont and Stein, 1999; Harter-Dreiman, 2004). This specification allows for fixed effects $\left(\lambda_{0 i}\right)$, momentum effects, and error correction. The inclusion of $\Delta p_{t-1}$ on the right hand side caters for the potential feedback in housing demand that can cause positive momentum effects in house price movements: high house price growth in the previous period induces greater price growth expectations for the current period thus increasing demand for housing and consequently the house price growth rate. Previous empirical examinations provide strong support for such momentum effects (Case and Shiller, 1989; Capozza et al., 2004; Dusansky and Koç, 2007; Røed Larsen and Weum, 2008; Beracha and Skiba, 2011). The error-correction term $\left[\lambda_{5}\left(p-p^{*}\right)_{i, t-1}\right]$ captures the sluggish adjustment of house prices towards the long-term equilibrium price level. The parameter $\lambda_{5}$ 
shows the speed of price adjustment towards $p^{*}$ per period. Obviously, both $\lambda_{4}$ and $\lambda_{5}$ are expected to be between zero and one. Finally, $\varepsilon$, is assumed to be white noise and have a zero mean.

Generally, empirical estimations of housing market dynamics that have been based on panel data are in line with (4) and (5) in that the long-term coefficients on market fundamentals and the shortterm dynamics are assumed to be the same across space. Nevertheless, some spatial heterogeneity is typically allowed by including area-specific fixed effects [i.e., the constant terms differ across locations: $\lambda_{0 i}$ in (5); this also would reflect $\beta_{0 i}$ instead of $\beta_{0}$ in (4)]. However, as we show above, the slope coefficients in (4) are dependent on the price elasticity of housing supply. Given that theory expects supply elasticity to vary substantially across cities and empirical evidence supports these theoretical models (Saiz, 2010; Paciorek, 2013), the assumption of similar coefficients across space seems unrealistic. In addition, the demand elasticities $\left(\gamma_{1}, \gamma_{2}, \gamma_{3}\right)$ may vary across cities. Moreover, there are good reasons to expect that the strength of the momentum effect $\left(\lambda_{4}\right)$ and the speed of adjustment towards long-term equilibrium $\left(\lambda_{5}\right)$ differ across housing markets (Capozza et al., 2004; Glaeser et al., 2008).

Therefore, we hypothesize that there are significant differences in long- and short-term house price dynamics across cities, and rewrite the equations for the long-term equilibrium house price level and the short-term price change by adding the subscript $i$ to all the parameters in the equations, thus allowing for heterogeneity of slope coefficients across cities:

$$
\begin{aligned}
& p_{i, t}{ }^{*}=\mathrm{h}\left(d_{i, t}{ }^{*}{ }_{i, t}{ }^{*}\right)=\beta_{0 i}+\beta_{1 i} y_{i, t}-\beta_{2 i} r_{t}+\beta_{3 i} c_{i, t}, \\
& \Delta p_{i, t}=\lambda_{0 i}+\lambda_{1 i} \Delta y_{i, t-1}-\lambda_{2 i} \Delta r_{i, t-1}+\lambda_{3 i} \Delta c_{i, t-1}+\lambda_{4 i} \Delta p_{i, t-1}-\lambda_{5 i}\left(p-p^{*}\right)_{i, t-1}+\varepsilon_{i, t}
\end{aligned}
$$

In our empirical analysis, we examine the extent of spatial heterogeneity across U.S. metropolitan area housing markets. We also relate spatial differences in house price dynamics to MSA-specific factors, the supply elasticity of housing in particular.

\section{Data}

Our empirical analysis is based on quarterly data for the 70 largest (as of 2015) continental U.S. MSAs or MSADs for which data were available for the period 1980Q1 through 2015Q2. ${ }^{3}$ The 70

\footnotetext{
${ }^{3}$ We limit the sample to the 70 largest MSAs or MSADs for which data are available because smaller areas tend to exhibit too much implausible volatility in the FHFA house price indexes and most lack complete data. Honolulu would have been ranked $58^{\text {th }}$ with respect to population, but was excluded due to extreme volatility in the early years of the
} 
MSAs contained more than half of the U.S. population in 2015. We use the Federal Housing Finance Agency (FHFA) all transactions house price indexes. The sample period includes notable price cycles in many of the cities, especially during the 2000s but also in the late 1980s through early 1990s. House prices were generally more volatile in coastal than in inland cities, particularly in the 2000s.

The mortgage interest rate data are also from FHFA. Annual construction cost data, in turn, are sourced from the RS Means database. The quarterly construction cost values are interpolated based on changes in the shelter only component of the urban CPI produced by the Bureau of Labor Statistics. Finally, the aggregate income series is from the Bureau of Economic Analysis. As the income series is annual, we interpolate quarterly values based on changes in the national GDP, which is also from the Bureau of Economic Analysis. ${ }^{4}$ In contrast with the house price, aggregate income, and construction cost series that are at the MSA level, the mortgage interest rate data are nationwide.

All the variables are specified in real terms. House prices and construction costs are deflated by the national urban CPI less shelter, while aggregate income and interest rates are deflated by the national urban CPI for all items. All the series except for the mortgage rate are in natural log form. Table 1 provides summary statistics for the variables.

[Table 1 here]

There are significant spatial variations in the growth rates of house prices and aggregate income. During our sample period, the real house price growth was negative in 17 MSAs, most of which are inland. The greatest price growth (annualized mean growth rate of 3.1\%) was observed in San Francisco, with Boston close behind. The real aggregate income growth, in turn, was the highest in Austin, followed by Las Vegas and Raleigh, and positive in all MSAs except Detroit. The spatial variation in construction cost growth was much smaller. The extremes with respect to $\Delta c$ were Phoenix and Tucson, both with mean annual values close to zero, and New York and Philadelphia, with growth rates of approximately $1 \%$.

While the hypothesis of equality of mean price growth rates across MSAs cannot be rejected apparently due to the price growth in many MSAs being close to the mean across all MSAs - it is evident that there are statistically significant variations between the MSAs, as indicated by the p-

price index. For MSAs that are divided into MSADs, we use the MSAD data because the FHFA indexes are available for MSADs, but not MSAs, in those cases. The date range 1980Q1-2015Q2 is constrained by the availability of data.

${ }^{4}$ The annual aggregate income values are assigned to the second quarter of each year. 
value of 0.005 in the test for equality of means in San Francisco and Oklahoma City (the MSAs with largest and smallest price growth). In addition, the hypothesis of equal price growth variances across MSAs can clearly be rejected. The spatial variation in income growth is highly statistically significant, but such significant variation is not observed in construction cost movements.

While there are significant differences across MSAs in the long-term means of price and income growth, Table 1 shows that the mean correlation coefficients between MSAs are significantly positive for each variable. For construction cost growth the mean correlation coefficient is even close to one.

Overall, the summary statistics indicate that, while construction cost and interest rate movements should not cause notable deviations in house price growth across MSAs at least over the long run, aggregate income trends should account for a major part of the variation in the long-term growth of fundamental house price levels. ${ }^{5}$ Hence, our discussion of the long-run estimates focuses on the results for aggregate income.

\section{Empirical analysis}

The econometric analysis of macro (or "market") level panel data must address some common complications. A well-established aspect of house price dynamics is cross-sectional (or spatial) dependence; if cross-sectional dependence is present in the data, then conventional estimators are likely to be biased. Holly et al. (2010) provide evidence of notable cross-sectional dependence in house prices across U.S. states and show that neglecting the influence of cross-sectional dependence can considerably bias coefficient estimates. Another common problem is non-stationarity of data.

Recent advances in panel econometrics have produced estimators that are consistent in the presence of cross-sectional dependence and non-stationary variables. Our empirical analysis utilizes these kinds of modern techniques of panel econometrics, in particular those introduced by Pesaran (2006, 2007), Eberhardt and Teal (2010), and Chudik and Pesaran (2015). These approaches are designed for data with cross-sectional dependence, and the estimators are suitable for non-stationary data that are cointegrated. Moreover, these methods allow for spatial heterogeneity in slope coefficients, which is important given the potentially substantial differences in house price dynamics across locations.

\footnotetext{
${ }^{5}$ This is in line with the findings of Van Nieuwerburgh and Weill (2010): an increase in wage dispersion has been the main factor driving house price dispersion across U.S. cities.
} 
Our empirical analysis includes three phases:

1) Checking the order of integration of the data.

2) Estimating the long-run equation (6). This phase also includes testing for panel cointegration as a specification check for the estimated long-run house price equation and investigating the extent of spatial heterogeneity in the long-run parameters.

3) Estimating the short-term house price equation (7) and examining the significance of heterogeneity in dynamics across MSAs.

For each phase, we report the cross-sectional dependence of model residuals to investigate whether it is appropriate to apply test procedures and estimators that allow for such dependence, and examine if the models designed for cross-sectionally dependent data are able to remove such dependence from the residuals. Furthermore, the final part of this section studies the implications of the estimation results for price cycles and the relationship between price dynamics and the supply elasticity of housing.

\subsection{Unit root tests}

We start with panel unit root tests to examine the stationarity of the data. As the residual series from conventional augmented Dickey-Fuller (ADF) regressions exhibit highly significant cross-sectional correlation (see Table 2), ${ }^{6}$ we report results based on the cross-sectional augmented IPS (CIPS) panel unit root test (Pesaran, 2007). The CIPS test filters out the cross-sectional dependence by augmenting the conventional ADF regressions with cross-sectional averages and is thus not biased by the presence of spatial dependence in the data. Furthermore, the CIPS test is based on the crosssectional augmented ADF (CADF) regressions that are conducted separately for each MSA, thereby allowing for spatial heterogeneity.

Table 2 presents the CIPS test statistics both with (for the levels) and without a trend in the CADF regressions and with lag lengths varying between 0 and 4 . The null hypothesis is that of nonstationarity, which is accepted for $p$ in all cases and for $y$ and $c$ in most cases. Since the $r$ series is the same for all MSAs, the unit root test for $r$ is just the conventional ADF test for individual series, for which the results are mixed. The inability to reject a unit root in $p$ is in line with previous empirical evidence, and with the theoretical and empirical evidence of upwards sloping housing supply curves in urban areas (e.g., Saiz, 2010; Paciorek, 2013).

\footnotetext{
${ }^{6}$ This is in line with the findings of Holly et al. (2010) regarding state-level U.S. data.
} 
Since the data clearly seem to include non-stationary components, there is a need to test for cointegration and apply estimators that are suitable for non-stationary data in the second phase of the empirical analysis. As expected, all the variables are stationary in differences.

[Table 2 here]

\subsection{Long-term dynamics}

Next, we estimate the long-term equations for house prices that correspond to (6). Given the potential endogeneity of regressors with respect to the dependent variable $(p)$, our preferred estimator for the long-run equations relies on the panel mean-group Fully Modified OLS (FMOLSMG) estimator (Pedroni, 2000, 2001). The individual FMOLS estimates are super-consistent and robust in the presence of variable endogeneity, when the variables are non-stationary and cointegrated (Pedroni, 2007). However, the FMOLS-MG estimator does not cater for crosssectional dependence. Hence, we augment each regression in the FMOLS-MG model with a "common dynamic process" to account for cross-sectional dependence, as proposed by Eberhardt and Teal (2010). This is called the augmented mean-group FMOLS estimator (FMOLS-AMG).

The augmented mean-group (AMG) estimator of Eberhardt and Teal (2010) has previously been used to examine phenomena such as the determinants of default risk (Saldías, 2013) and interest rates (Lanzafame, 2016), and the relationship between energy intensity, income, urbanization, and industrialization (Sadorsky, 2013). In contrast with our analysis, the above mentioned studies rely on the standard mean-group (MG) estimator of Pesaran and Smith (1995), instead of FMOLS-MG, augmented with the common dynamic process. The present study is the first to apply the AMG approach to analyze house price dynamics.

The aim of incorporating the common dynamic process is to remove cross-sectional correlation from the long-term model by identifying common trends that are caused by unobservable factors. While $r$ is the same for each MSA and can therefore be regarded as a common fundamental factor for all MSAs, the influence of $r$ is not included in the common dynamic process because $r$ is not unobservable in our estimations. The common dynamic process is estimated first using a standard pooled OLS regression:

$$
\Delta p_{i, t}=\delta_{1} \Delta y_{i, t}-\delta_{2} \Delta r_{t}+\delta_{3} \Delta c_{i, t}+\sum_{t=2}^{T} \mu_{t} \Delta D_{t}+e_{i, t}
$$


In (8), $D_{t}$ are quarterly dummies, $T$ is the length of the sample period, and $e$ is the error term. In the second stage, the 70 MSA-specific FMOLS regressions for the levels are augmented with the $T-1$ coefficient estimates, $\hat{\mu}_{t}$ :

$$
p_{i, t}=\beta_{0 i}+\beta_{1 i} y_{i, t}-\beta_{2 i} r_{t}+\beta_{3 i} c_{i, t}+d_{i} \hat{\mu}_{t}+e_{i, t}
$$

In (9), $\hat{\mu}_{t}$ represents an estimated cross-group average of the evolution of unobservables over time (referred to as the common dynamic process). The model also contains MSA-specific intercepts $\left(\beta_{0 i}\right)$ to cater for any unobserved time-invariant fixed effects.

For comparison, we report mean-group estimation results for the long-run relation based on several other estimators in addition to FMOLS-MG and FMOLS-AMG. Table 3 provides a summary of the mean group panel estimation methods that we employ.

[Table 3 here]

The alternative estimators include the standard mean-group (MG) estimator, the Pesaran (2006) common correlated effects mean group (CCEMG) estimator, and the Chudik and Pesaran (2015) dynamic CCEMG (DCCEMG) estimator. The MG estimator allows for spatial heterogeneity and is suitable for non-stationary but cointegrated data, but does not cater for cross-sectional dependence. The CCEMG estimator is based on MG, but aims to remove the biasing impact of spatial dependence by including the cross-sectional averages of the dependent and independent variables as additional regressors. The DCCEMG approach additionally includes lagged cross-sectional means of dependent variables aiming to remove bias due to weakly exogenous regressors. ${ }^{7}$ While allowing for regional heterogeneity and aiming to control for cross-sectional dependence, the (D)CCEMG estimators can exhibit bias due to endogeneity. An additional potential complication with the (D)CCEMG estimators is that, due to the several additional variables (that aim to remove crosssectional dependence) compared with the fundamental long-term relation (6), the slope coefficient estimation may no longer be super-consistent. Hence some of the attractive robustness features that usually come with super-consistent estimation under cointegration are potentially lost (Pedroni, 2007). Such a complication is less likely with the FMOLS-AMG estimator, as that includes only one variable to control for spatial dependence. Indeed, it turns out that the (D)CCEMG estimators do not work well in the estimation of long-term relations in our data, which is likely due to these complications.

\footnotetext{
${ }^{7}$ The cross-sectional mean of a variable that is the same for all locations - like $r$ in our data - is not included in either of the CCEMG estimators, since the variable itself equals its cross-sectional mean.
} 
We follow Holly et al. (2010) and investigate model stationarity (i.e., whether the models are cointegrated) based on the CIPS test. This works as a specification check for the estimated relations: if the null hypothesis of non-stationarity is rejected, we can conclude that the estimated relationship is a long-term equilibrium equation. The long-run equation (10) that is tested for stationarity does not incorporate the effects of the common dynamic process or cross-sectional means:

$$
\hat{\epsilon}_{i, t}=p_{i, t}-\hat{\beta}_{0 i}+\hat{\beta}_{1 i} y_{i, t}-\hat{\beta}_{2 i} r_{t}+\hat{\beta}_{3 i} c_{i, t}\left[=\left(p-p^{*}\right)_{i, t}\right]
$$

For cointegration to be present, $\hat{\epsilon}$ needs to be stationary. Again, spatial heterogeneity in the CADF coefficients is allowed in the CIPS test.

Table 4 reports the estimated mean group (i.e., the mean of $\beta_{j, i}$ across MSAs) coefficients for the long-term price equation based on the five different estimators. The reported standard errors are computed following Pesaran and Smith (1995). All of the mean-group estimates in the FMOLSAMG model have the expected signs, and. While the estimates are statistically significant for $y$ and $c_{\bar{y}}$. Because of the way that the common dynamic process is computed, the long-term elasticity is not identified (in the FMOLS-AMG model) for $r$, thatwhich does not vary across MSAs-coefficient en $r$ is insignificant. This is not a notable-complication here, since $r$ works as control variable in the model and it is the income elasticity that we are-interests used in. ${ }^{8}$ In any case, This is not totally unexpected given that the real interest rate is generally assumed to be mean-reverting in the long $\operatorname{run}_{2} \cdot{ }^{-}$and Aa mean-reverting variable is generally not expected to have a notable effect on longterm relations for non-stationary variables. $\frac{10}{}$

[Table 4 here]

The MG and FMOLS-MG estimators, which do not cater for cross-sectional dependence, result in slightly different estimates. For instance, In particular, the coefficient on $y$ is somewhat smaller. Also, the sign on $r$ is unexpected (positive) instead of negative and the coefficient on $y$ is somewhat smaller. The cross-sectional correlation in the MG and FMOLS-MG models is large, 0.59 and 0.34 respectively, underscoring the need for controlling cross-sectional dependence. The FMOLS-AMG estimator eliminates practically all of the cross-sectional dependence; the remaining cross-sectional correlation in the residuals is only $0.0 \underline{0} 1$ and the hypothesis of no cross-sectional correlation is

${ }^{8}$ The estimates on $y$ and $c$, and their standard errors, are exactly the same regardless of whether the common dynamic process is estimated with or without $r$ in equation (8). The results of the empirical analysis would be similar even if $r$ was excluded from the long-term model.

${ }^{9}$ The relatively short sample periods and low power of $A D F$ or other unit rogt tests often do not provide enough evidence to reject the null of a unit reot; in our case, the unit rogt test evidence on $r$ reperted in Table 2 is mixed. ${ }^{10}$ The relatively short sample periods and low power of ADF or other unit root tests often do not provide enough evidence to reject the null of a unit root; in our case, the unit root test evidence on $r$ reported in Table 2 is mixed. 
accepted by the Pesaran (2004) CD test. In addition, the standard errors of coefficient estimates are notably smaller in the FMOLS-AMG model than in the other models.

The (D)CCEMG results deviate substantially from the FMOLS-AMG ones. Moreover, in contrast with the FMOLS-AMG estimates, (D)CCEMG yields a number of large negative MSA-specific coefficients on $y$. A further complication with the equations provided by (D)CCEMG estimators is that they do not appear to be cointegrated. These problems may be due to the potential complications with the (D)CCEMG estimators when applied to the long-term equations, as discussed above. All in all, the FMOLS-AMG estimator appears to provide more reliable estimates and thus also works as a more reliable basis for the error-correction mechanism in the short-term analysis.

Based on the preferred FMOLS-AMG model, the mean of the MSA-specific long-term elasticities of house prices with respect to aggregate income is 0.81 . Corresponding estimates for $c$ and $r$ areis 0.07 and 0.01 , respectively. These parameter signs are in line with the theory according to which higher aggregate income increases demand for housing and thereby the price level, while higher interest rates do the opposite. Hhigher construction costs, in turn, are expected to reduce housing supply and thereby to be associated with higher house price levels. The mean-group income elasticity estimate is somewhat smaller than that reported by Holly et al. (2010) based on the CCEMG estimator (1.14), but substantially greater than many previous estimates that have been based on estimators that do not allow for spatial heterogeneity and do not control for cross-sectional dependence and endogeneity (e.g., Capozza et al, 2004; Harter-Dreiman, 2004).

The models allow us to investigate formally whether the spatial differences in the long-term slope coefficients are statistically significant. For the MG and (D)CCEMG models we use the Swamy test of slope homogeneity of Pesaran and Yamagata (2008). ${ }^{11}$ For the FMOLS models, in turn, the sizeadjusted F-test proposed by Pedroni (2007) is used. These tests clearly reject the null hypothesis of homogeneous slope coefficients in all models, indicating that the spatial differences in long-term dynamics are indeed of importance.

Regarding differences across MSAs, we concentrate on the variation in income elasticity. Aggregate income is the determinant of $p^{*}$ that is trending, while $c$ and $r$ do not exhibit notable long-term trends but rather tend to be close to constant over the long horizon. Also, $y$ is the

\footnotetext{
${ }^{11}$ This test has the correct size and satisfactory power in panels with exogenous regressors and in dynamic panels if the autoregressive coefficient is not too close to unity. The long-term models reported in Table 4 may include endogenous regressors. However, the very small p-values $(<0.001)$ in the Swamy and F-tests are a clear indication of heterogeneous slope coefficients.
} 
fundamental whose growth over time varies significantly across MSAs. That is, the growth in $y$ together with the income elasticity of house prices determine MSA-specific house price growth and its variation across MSAs over the long run.

Income elasticity exhibits substantial spatial differences. Figures 1 and 2 show frequency and geographic distributions of the income elasticities, respectively. The largest observed elasticity is 2.73 for Detroit, while the smallest is 0.05 for Fort Worth. Detroit differs quite substantially from the other MSAs, since the second largest value is 1.64 for Los Angeles. In line with the considerations of Glaeser and Gyourko (2005), the high income elasticity in Detroit appears to be related to the fact that it is the only MSA in our sample that experienced a decline in real aggregate income between 1980 and 2015. While real house prices were declining rapidly in Detroit in the late 2000s and early 2010s, real aggregate income was also declining, although at a slower rate. The geographic distribution of income elasticities generally conforms with expectations, with higher elasticities found mostly in coastal and some lakefront locations and clustering of similar elasticities. Houston and Salt Lake City are exceptions, with low and high elasticities in coastal and inland locations, respectively.

[Figures 1 and 2 here]

While the group-mean estimates become increasingly reliable as the number of cross-sections increases, the MSA-specific point estimates may not be very accurate (Pedroni, 2007). This is the case especially with the estimates on $c$ and $r$ given their relatively small variations over time; for $y$ this should be less of a problem given its substantial time-variation. While acknowledging that some individual coefficients can be unreliable and the MSA-specific estimates (on $c$ and $r$ in particular) as well as their correlations across MSAs should be taken cautiously, the crosscorrelations between coefficient estimates based on a large number of MSAs are expected to reflect the actual correlation structure. The estimated income and interest rate elasticities are negatively $(0.34)$ and significantly correlated across MSAs, as expected. In contrast, we report that the crosscorrelations between estimated construction cost elasticity and income the other elasticityies are is small and insignificant (we do not explore cross-correlations for the estimates on $r$ given that those are not identified). Obviously, some unreliable individual coefficient estimates may diminish the cross-correlations.

It also is worth noting that, although the mean-group estimates differ somewhat between the FMOLS-AMG and FMOLS-MG models, the MSA-specific estimates from these models are strongly correlated: the correlation coefficient is 0.96 for income elasticity (excluding Philadelphia, 
which is a clear outlier) and, 0.95 for construction cost elasticity, and 0.72 for the interest rate elasticity.

The considerable variation in income elasticity across MSAs can be explained by spatial variation in the supply elasticity of housing and in the price and income elasticities of housing demand: as shown above, $\beta_{1}=\gamma_{1} /\left(\gamma_{3}+\phi_{1}\right)$. Given the large spatial variation in the price elasticity of supply of housing (Saiz, 2010), it is expected that the supply side accounts for a major part of the differences in $\beta_{1}$. The influence of supply elasticity is also of special interest, as it is the supply elasticity in particular that can be affected directly by national and especially local policies and regulations. Moreover, many leading urban economists emphasize today the influence of housing supply elasticity as a key determinant not only of house price dynamics but also of metropolitan growth dynamics (e.g., Glaeser et al., 2006; Glaeser and Gottlieb, 2009; Saiz, 2010; Gyourko et al., 2013). In particular, more inelastic housing supply and hence greater income elasticity of house prices can work as a significant counterforce for city growth and regional centralization.

Figure 3 illustrates the relationship between the price elasticity of supply reported by Saiz (2010) and the estimated elasticity of house price level with respect to aggregate income at the MSA level. ${ }^{12}$ The income elasticities are based on the FMOLS-AMG estimation. As expected, generally the more inelastic housing supply is, the greater is the income elasticity. The simple correlation between these two elasticities is -0.59 (-0.68 without the outlier Detroit, which is not included in the graph). The strong negative relationship between income elasticity of house prices and supply elasticity, in particular, is why supply elasticity significantly affects metropolitan growth dynamics (Saks, 2008; Gyourko et al., 2013).

[Figure 3 here]

Although the supply elasticity is likely to vary more across MSAs and can generally be influenced more by various policy tools than housing demand elasticities, it is also interesting to ponder the role of demand elasticities. The elasticity of housing demand with respect to income and own price can vary across cities because of differences in demographic factors (e.g., Mayo, 1981). Albouy and Lue (2015) present evidence that many relevant demographic factors vary relatively little across MSAs. Nevertheless, given that the explanatory power in a simple regression between income elasticity of price and supply elasticity is approximately 50\% as shown in Figure 3, it is clear that spatial variations in the demand elasticities too must explain part of the variation in the income

\footnotetext{
${ }^{12}$ All of the figures, coefficients, and correlations that include the supply elasticity exclude Anaheim and Sacramento since Saiz (2010) does not report the elasticities for these MSAs.
} 
elasticity of prices. Unfortunately, we were not able to find MSA-level demand elasticity estimates to explore the relative importance of the supply and demand elasticities. ${ }^{13}$

The demand elasticities could be correlated, to some extent, with the supply elasticity. For instance, the Stone-Geary demand function suggests that the demand elasticities are smaller (in absolute value) when house prices (relative to other prices) are higher (Mayo, 1981). This implies that supply elasticity is positively correlated with income elasticity of demand and with the absolute value of price elasticity of demand, since relative house prices generally are higher in the more supply restricted cities. From $\beta_{1 i}=\gamma_{1 i} /\left(\gamma_{3 i}+\phi_{1 i}\right)$ we see that, while positive correlation between $\gamma_{3 i}$ (absolute value of price elasticity of demand) and $\phi_{1 i}$ (supply elasticity) may overstate the explanatory power of $\phi_{1 i}$ in a pairwise regression between $\beta_{1 i}$ (income elasticity of price) and $\phi_{l i}$, the positive correlation between $\gamma_{1 i}$ (income elasticity of demand) and $\phi_{1 i}$ does the opposite. Due to these offsetting effects it seems unlikely that the presented pairwise regression would notably overstate the "pure" explanatory power of supply elasticity on cross-sectional variation in the income elasticity of price. ${ }^{14}$

\subsection{Short-term dynamics}

In the third step, we focus on short-term house price dynamics, with the momentum effect and adjustment speed towards long-run equilibrium being our main interests. In the error-correction part of the short-term model, we use the MSA-specific deviations of the house price levels from their long-term equilibrium levels [given by (10)] based on the FMOLS-AMG estimates. ${ }^{15}$ For comparison purposes, we estimate equation (7) with several alternative estimators to see the impact

\footnotetext{
${ }^{13}$ For a recent study discussing and investigating the demand elasticities at the national level, see Albouy et al. (2016).

${ }^{14}$ Some fraction of the variation in $\beta_{1}$ would remain unexplained even if we were able to include demand elasticity estimates in the regression. That is, the demand elasticities are not expected to explain the whole $49 \%$ fraction of variation in $\beta_{l}$ that remains unexplained.

${ }^{15}$ The deviation from the long-run fundamental price level for each MSA is computed as in (10), i.e., excluding the influence of the common dynamic process. In principle, the common dynamic process could include national-level shocks that should be considered fundamentals. However, the common dynamic process is expected to include nonfundamental elements as well. Therefore, including this process in the computed long-run fundamental price levels might in many cases lead to the process "explaining" a high (or low) price level, even a "bubble", in a given MSA due to high price levels in other MSAs even if market fundamentals would not justify such price levels. Indeed, if the common dynamic process is included in the long-run relations, the deviations from those relations would suggest that there were notable (at least 20\%) overvaluations only in a small number of MSAs during the first decade of the 2000 s. Instead, such an approach would suggest that housing was considerably undervalued in a large number of MSAs where price levels did not increase substantially during the early 2000s. Moreover, the CIPS test works as a specification test for the long-run relations that exclude the effects of the common dynamic process [as shown in equation (10)]. If other fundamentals than $y, c$, and $r$ were driving house prices in the long term, we would expect the CIPS test to accept the null hypothesis of non-stationary $\hat{\epsilon}_{i, t}$. However, the CIPS statistics clearly reject the null hypothesis.
} 
of the potential biases on the estimates computed with conventional estimators that do not cater for cross-sectional dependence.

In Table 5, the OLS model refers to the conventional pooled fixed-effects Ordinary Least Squares estimator that corresponds to equation (5) by not allowing for spatial heterogeneity in the slope coefficients. For the other models, the coefficient estimates reported in Table 5 represent the mean coefficients across MSAs. RE refers to the Random Effects estimator that allows for heterogeneity in dynamics through random intercepts and slope coefficients. The MG estimator also allows for spatial heterogeneity in the estimates. These three "conventional" estimators yield momentum parameters of around 0.3 and significant but very slow adjustment speeds of prices (approximately 2-3\% per quarter) towards the long-run fundamental level. The other estimated parameters for the lagged variables, except those on $\Delta c$, are also statistically significant at the $5 \%$ level, but the coefficients on $\Delta r$ have unexpected signs. As expected, the residual cross-sectional correlation in these models is large (around 0.4).

[Table 5 here]

Given that the conventional panel OLS, RE, and MG estimates can be biased in the presence of cross-sectional dependence, Table 5 also reports the results based on the (D)CCEMG estimators. ${ }^{16}$ DCCEMG is the preferred estimator, since all of the other estimators in Table 5 can, in principle, suffer from the "Nickell bias" (Nickell, 1981) due to the inclusion of the one-period lagged dependent variable as an explanatory variable. While the differences between CCEMG and DCCEMG estimates are small, the coefficients computed with DCCEMG exhibit several notable differences compared with those estimated with the OLS, RE, and MG estimators: (1) the momentum parameter is smaller; (2) the adjustment speed towards the long-run equilibrium level is notably greater; (3) the coefficients on lagged income and lagged construction costs are substantially larger; and (4) the coefficient on $\Delta r$ is insignificant. Hence, while cross-sectional dependence appears to cause notable bias in the OLS, RE, and MG coefficient estimates, the biases induced by the lagged dependent variable in the CCEMG estimates are not that large (given our data). The remaining cross-sectional correlation in the DCCEMG model is negligible (-0.003) and insignificant at the $5 \%$ level. Note that - because of the very large number of observations $(9,800)-$ the $\mathrm{CD}$ test tends to reject the null hypothesis even when the cross-sectional correlation is very small, as is the case with the CCEMG model.

\footnotetext{
${ }^{16}$ We do not report the short-term model based on FMOLS, since that estimator is aimed especially at cointegrating relations and does not possess similar advantages over (D)CCEMG estimators in the short-term analysis as in the longterm model.
} 
The quarterly adjustment speed of prices towards the steady-state level is approximately 5\% and highly significant in models [4] and [5]. This adjustment speed estimate is of similar magnitude to that reported in many previous studies (e.g., Capozza et al., 2004; Harter-Dreiman, 2004; Holly et al., 2010). The negative sign on the adjustment coefficient - higher house price levels compared with long-term equilibrium levels predict lower future price growth - further implies that the estimated long-term model works as it should: house prices tend towards the long-term fundamental level. Interestingly, the smaller coefficients on lagged price change (smaller momentum effect) in models [4] and [5] than in models [1] to [3] suggests that the relatively large momentum parameters often reported for U.S. MSAs (based on estimators that do not control for cross-sectional dependence) may exaggerate the actual momentum effect. However, the parameter on lagged price change remains highly significant in models [4] and [5].

The Swamy test clearly rejects the hypothesis of slope homogeneity in models [3] through [5] for which the test is applicable. Figure 4 shows frequency distributions for the DCCEMG momentum and reversion estimates. Again, the MSA-specific point estimates should be taken with some caution. While the estimates show substantial variation across MSAs, for most MSAs the reversion speed estimate is less than $7.5 \%$ per quarter. Similar to the long-term income elasticity, the momentum effect is significantly related to the supply elasticity: the momentum effect is generally greater in the MSAs with more inelastic supply of housing, the correlation between the momentum parameter and supply elasticity being -0.36 . This is in line with the often stated argument that the more supply-restricted locations are more prone to notable house price overshoots and subsequent price drops. The reversion speed is not correlated with supply elasticity, however. ${ }^{17}$

[Figure 4 here]

\footnotetext{
${ }^{17}$ As a check of the robustness of our panel estimation results, we undertook the analysis using a different set of house price indexes obtained from CoreLogic. These indexes differ from the FHFA indexes in that they are not limited to houses with mortgages securitized by Fannie Mae and Freddie Mac. However, we were able to obtain the CoreLogic indexes for only the 25 largest MSAs in our sample. Consequently, we also repeated the analysis using the FHFA price indexes for the 25 largest MSAs. This in effect provides two types of robustness checks, one due to varying the house price data and the other to changing the sample of MSAs. Visual comparison of the CoreLogic and FHFA price indexes indicates that they are broadly similar for all of the 25 MSAs except for Houston, where the two indexes diverge during the 1980s and remain on separate paths thereafter. The FMOLS-AMG long-run mean estimates for the three sets of data, including our main sample of 70 MSAs, are practically the same, with no significant differences for any of the three coefficients. At the MSA level, the correlations between the coefficients for the two 25-MSA estimations are 0.95 , 0.67, and 0.89 for income, construction costs, and interest rates, respectively. The correlations between the two sets of coefficients based on FHFA data (using just the largest 25 MSAs from the 70-MSA estimation) are 0.99, 0.98, and 0.99. Clearly, our baseline long-run results are robust with respect to reducing the sample size and using an alternative house price index. Not surprisingly, the short-run results are also virtually the same across the three sets of data.
} 


\subsection{Price cycles around the fundamental price level}

Figure 5 shows the deviation of house price levels from the estimated long-run relation in each MSA using the same long-run fundamental price levels as in the estimation of short-term dynamics. We have clustered the 70 MSAs into 11 different regional groups. This division illustrates how house price cycles around the long-term fundamental price level generally are highly synchronized across MSAs within the same region, while there typically are notably greater differences in the deviations from the fundamental price level between cities located far from each other. The average correlation of deviations is 0.75 within geographic groups, while it is 0.47 between MSAs that do not belong in the same geographic group.

Importantly, Figure 5 shows that house price levels adjust towards the estimated long-run relations, i.e., prices do not trend away from our long-run equilibrium levels in any of the MSAs but rather cycle around them. This visual inspection works as an additional check for the stationarity of the long-term relations and provides further support for the argument that these relations can be considered as long-term equilibrium relations. Thus, the deviations from estimated relations can also meaningfully be used to investigate the occurrence of price bubbles, even though there can be also other fundamental factors that influence housing demand and thus price dynamics at least in the short run (if there were omitted non-stationary factors that influence house price levels in the long run, the deviations from estimated long-run levels would be expected to be non-stationary).

\section{[Figure 5 here]}

The theoretical model of Glaeser et al. (2008) suggests that, if housing supply is sufficiently elastic, then a "temporary burst of irrational exuberance" does not lead to large and long-lasting price increases; instead, the emerging bubble disappears fast. In contrast, if housing supply is inelastic and if we assume adaptive expectations (which are well supported by the empirical literature), a positive demand shock causes a greater short-term price reaction, expectations of future price increases remain high, and additional price growth is induced. The Glaeser et al. (2008) model further suggests that long-lasting bubbles can take place only in cities with highly inelastic housing supply. Hence, bubbles are expected to be larger and longer-lasting in the comparatively inelastic MSAs. Eventually, prices have to converge back towards the fundamental level, but this convergence typically involves an undershoot; i.e., house prices tend to drop below the fundamental level after a notable overshoot. In line with their theoretical considerations, Glaeser et al. (2008) show that the notable price run-ups of the 1980s in the U.S. were almost exclusively experienced in 
cities where housing supply is relatively inelastic. Similarly, the largest price increases from 1996 to 2006 took place, with a couple of exceptions, in the inelastic markets.

While Glaeser et al. (2008) concentrate on comparing price growth rates across cities, we provide further evidence on the relationship between supply elasticity and house price dynamics by investigating the relationship between elasticity of supply and overvaluation relative to an estimated long-term equilibrium price level. This is worthwhile, since greater price growth does not straightforwardly define a price bubble, as faster price growth can be related to more rapid income and population growth as well as to greater long-run income elasticity of house prices. In theory, the faster run-ups in the more supply-restricted areas could be due to differing market fundamentals.

Figures 5 and 6 reveal that it is mostly the coastal cities that have experienced drastic house price overshoots and cycles around fundamental price levels. That is, quite intuitively, demand increases induce greater initial price growth in the more supply-restricted cities - that are typically coastal cities - which yields greater future price growth expectations for backward-looking agents. The greater expectations can fulfill themselves, up to a point, and subsequently drive house price levels farther away from long-term fundamental price levels. The correlation of momentum parameters with supply elasticity provides further reasons for the observed notable price overshoots in the supply-inelastic MSAs.

[Figure 6 here]

Figure 7 illustrates the relationship between price bubbles and supply elasticity by showing that the notable price bubbles in the first decade of the 21 st century - defined as at least a $20 \%$ deviation above the estimated fundamental price level - have been concentrated in the relatively supplyinelastic MSAs. ${ }^{18}$ The vertical dashed line shows the average supply elasticity (1.68), while the horizontal dashed line indicates the $20 \%$ threshold. The large overshoots took place almost exclusively in the MSAs with lower than average supply elasticity (only three MSAs had large overshoots and above average supply elasticities). Indeed, in $80 \%$ of cities with lower than average supply elasticity, the maximum price overshoot was more than $20 \%$, and the simple correlation between the peak of overshoot and supply elasticity is -0.59 and statistically highly significant. Similarly, the correlation between price overshoot in the 1980s and supply elasticity is -0.58 . Table 6 lists the elasticity values and bubble figures for the 2000s for the MSAs in our sample.

\footnotetext{
${ }^{18}$ In line with Glaeser et al. (2008), we chose the value $20 \%$ to ensure that house prices really are substantially above the long-run fundamental level.
} 
[Figure 7 here]

[Table 6 here]

We further test the implications of the Glaeser et al. (2008) model by regressing both bubble size and duration (measured as the number of successive quarters for which prices were at least $20 \%$ above equilibrium) in the 2000s on supply elasticity (Table 7). In addition to supply elasticity, aggregate income growth is a likely factor contributing to the size and duration of the bubbles, as greater demand growth induces faster price growth and thereby greater expected growth (assuming adaptive expectations). Hence, Table 7 also reports simple cross-sectional OLS regressions for the bubble variables using the difference between the maximum level of $y$ during 1996-2007 and $y$ as of 1996Q1 ("growth of $y$ ") as an additional explanatory variable. ${ }^{19}$ Year 1996 is selected as the base year for the growth rate as in Glaeser et al. (2008), since 1996 presents the turning point in real house price indices, and 2007 generally is the last year when price peaks were observed in these MSAs. Both supply elasticity and growth in $y$ are highly significant and together explain $44 \%$ of bubble size and $46 \%$ of duration across MSAs. ${ }^{20}$

[Table 7 here]

While these regressions are coarse and growth in $y$ may be endogenous to price bubbles, it is reassuring that the coefficients on supply elasticity are not notably affected by the inclusion of demand growth in the regressions. The coefficient estimates suggest that a one-unit smaller supply elasticity caused a $16 \%$ percentage points larger and seven quarter longer price bubble in the 2000s, on average. All in all our findings provide support for the theoretical model of Glaeser et al. $(2008){ }^{21}$

Finally, Figure 8 shows that while the cross-correlation between momentum and equilibriumadjustment parameters is small, all the MSAs with very large momentum parameters $(>0.50)$ had notable bubbles during the first decade of 2000s. Based on simple cross-sectional OLS regressions, momentum is, as expected, significantly associated with larger and longer-lasting bubbles, whereas equilibrium-adjustment speed is not. Another cross-sectional regression indicates that momentum is

\footnotetext{
${ }^{19}$ We also estimated models that include the squared explanatory variables. These models do not show evidence of significant non-linearity in the effects.

${ }^{20}$ Huang and Tang (2012) also find a positive relationship between bubble size and supply constraints.

${ }^{21}$ In contrast to Glaeser et al. (2008) and our findings, Davidoff (2013) concludes that there is no evidence supporting the view that differences in supply elasticity caused cross-sectional variation among U.S. housing markets in the severity of the 2000s housing cycle. While Davidoff (2013) uses three different measures for the severity of the cycle price growth rates, price growth rate volatilities, and the price difference between peak of the boom and the lowest price level in the consequent bust - he does not relate house price levels to long-run equilibrium house price levels.
} 
generally greater in the more supply restricted MSAs and faster growing cities, which is consistent with the models presented in Capozza et al. (2004) and Glaeser et al. (2008).

[Figure 8 here]

\section{Conclusions}

We use recent advances in panel econometrics to investigate house price dynamics in the 70 largest U.S. MSAs. These methods allow for spatial heterogeneity, take account of cross-sectional dependence, and are suitable for non-stationary but cointegrated data. The study adds to the literature on spatial heterogeneity in house price dynamics and includes several innovations compared with previous studies.

We estimate the mean long-term elasticity of house prices with respect to aggregate personal income to be 0.81 ; however, this varies considerably across MSAs. The MSA-level long-term income elasticity is negatively and significantly associated with the price elasticity of housing supply. House price cycles around long-term fundamental price levels are generally highly synchronized across MSAs within the same region, while there are substantially greater differences in the timing and magnitude of these cycles between more distant cities. This points to important region-specific demand shocks that drive house price cycles in MSAs within the same geographic part of the country.

The short-term momentum and reversion dynamics also show substantial spatial heterogeneity that can notably influence the extent of house price cycles. The analysis provides empirical evidence supporting the theoretical model of Glaeser et al. (2008): house price bubbles tend to be larger and longer-lasting in the MSAs with more inelastic housing supply. Indeed, the notable overvaluations of the 2000s have occurred mainly and have lasted longer in supply-inelastic MSAs.

The analysis is also a test of the validity of conventional panel models - that assume homogeneous dynamics across space and neglect cross-sectional dependence - in the analysis of housing market dynamics. Given the considerable variations across locations, the use of estimators that allow for heterogeneous dynamics is warranted. Allowing for spatially heterogeneous dynamics is likely to yield more accurate estimates of: equilibrium house price levels and consequently measures of bubbles; housing market outcomes of national and local policy actions; metropolitan growth prospects; and the riskiness of local housing markets. Thus the results have important macroeconomic implications: as Piazzesi and Schneider (2016) point out, a major question 
regarding the nexus between macroeconomics and housing is whether national housing markets should be viewed at the country level or treated as a "collection of small countries" identified with MSAs or other regional units.

Our results also suggest that the ability to take account of cross-sectional dependence can significantly affect coefficient estimates. Conventional panel estimators that do not consider crosssectional dependence can yield overly large estimates for the house price momentum effect, estimated adjustment speeds towards long-run equilibrium levels that are too slow, and incorrect parameter signs. While we provide evidence on the relationship between house price dynamics and supply elasticity of housing, the role of the demand elasticities that underlie variations in house price dynamics across MSAs would be an interesting topic to study in detail in the future.

\section{Acknowledgments}

For helpful comments, we thank Dan McMillen and other participants at the 2017 FSU-UF Critical Issues in Real Estate Symposium, two anonymous referees, and the editor. We thank Sam Khater for providing the CoreLogic house price indexes, Albert Saiz for giving supply elasticity data, and Andrew VanValin for preparing the maps.

Funding: This work was supported by the OP-Pohjola Group Research Foundation and the Academy of Finland (first author; grant number 268310).

\section{References}

Abraham, J. M. and Hendershott, P. H. (1996). Bubbles in metropolitan housing markets. Journal of Housing Research, 7(2), 191-207.

Albouy, D., Ehrlich, G. and Liu, Y. (2016). Housing demand, cost-of-living inequality, and the affordability crisis, NBER Working Paper 22816.

Albouy, D. and Lue, B. (2015). Driving to opportunity: local rents, wages, commuting costs and sub-metropolitan quality of life. Journal of Urban Economics, 89, 74-92.

Anundsen, A. K. and Heebøll, C. (2014). Regional US house price formation: one size fits all? Norges Bank Research Paper 08/2014.

Beracha, E. and Skiba, H. (2011). Momentum in residential real estate. Journal of Real Estate Finance and Economics, 43(3), 299-320. 
Capozza, D. R., Hendershott, P. H. and Mack, C. (2004). An anatomy of price dynamics in illiquid markets: analysis and evidence from local housing markets. Real Estate Economics, 32(1), 1-32.

Case, K. E. and Shiller, R. J. (1989). The efficiency of the market for single-family homes. American Economic Review, 79(1), 125-137.

Chudik, A. and Pesaran, M. H. (2015). Common correlated effects estimation of heterogeneous dynamic panel data models with weakly exogenous regressors. Journal of Econometrics, 188(2), 393-420.

Davidoff, T. (2013). Supply elasticity and the housing cycle of the 2000s. Real Estate Economics, 41(4), 793-813.

DiPasquale, D. and Wheaton, W. C. (1992). The markets for real estate assets and space: a conceptual framework. Real Estate Economics, 20(1), 181-197.

DiPasquale, D. and Wheaton, W. C. (1994). Housing market dynamics and the future of housing prices. Journal of Urban Economics, 35(1), 1-27.

Dusansky, R. and Koç, Ç. (2007). The capital gains effect in the demand for housing. Journal of Urban Economics, 61(2), 287-298.

Eberhardt, M. and Teal, F. (2010). Productivity analysis in global manufacturing production. Discussion Paper 515, University of Oxford, Department of Economics.

Genesove, D. and Mayer, C. (2001). Loss aversion and seller behavior: evidence from the housing market. Quarterly Journal of Economics, 116(4), 1233-1260.

Glaeser, E. L. and Gottlieb, J.D. (2009). The wealth of cities: agglomeration economies and spatial equilibrium in the United States. Journal of Economic Literature, 47(4), 983-1028.

Glaeser, E. L. and Gyourko, J. (2005). Urban decline and durable housing. Journal of Political Economy, 113(2), 345-375.

Glaeser, E. L., Gyourko, J., Morales, E. and Nathanson, C. G. (2014). Housing dynamics: an urban approach. Journal of Urban Economics, 81, 45-56.

Glaeser, E. L., Gyourko, J. and Saiz, A. (2008). Housing supply and housing bubbles. Journal of Urban Economics, 64(2), 198-217.

Glaeser, E. L., Gyourko, J. and Saks, R. E. (2006). Urban growth and housing supply. Journal of Economic Geography, 6(1), 71-89.

Gyourko, J., Mayer, C. and Sinai, T. (2013). Superstar cities. American Economic Journal: Economic Policy, 5(4), 167-199.

Harter-Dreiman, M. (2004). Drawing inferences about housing supply elasticity from house price responses to income shocks. Journal of Urban Economics, 55(2), 316-337. 
Holly, S., Pesaran, M. H. and Yamagata, T. (2010). A spatio-temporal model of house prices in the USA. Journal of Econometrics, 158(1), 160-173.

Holly, S., Pesaran, M. H. and Yamagata, T. (2011). The spatial and temporal diffusion of house prices in the UK. Journal of Urban Economics, 69(1), 2-23.

Huang, H. and Tang, Y. (2012). Residential land use regulation and the US housing price cycle between 2000 and 2009. Journal of Urban Economics, 71(1), 93-99.

Lai, R. N., and Van Order, R. (2017). U.S. house prices over the last 30 years: bubbles, regime shifts and market (in)efficiency. Real Estate Economics, 45(2), 259-300.

Lamont, O. and Stein, J. C. (1999). Leverage and house-price dynamics in U.S. cities. Rand Journal of Economics, 30(3), 498-514.

Lanzafame, M. (2016). Inflation targeting and interest rates: a panel time-series approach. Oxford Economic Papers, 68(2), 484-505.

Mayo, S. K. (1981). Theory and estimation in the economics of housing demand. Journal of Urban Economics, 10(1), 95-116.

Nickell, S. (1981). Biases in dynamic models with fixed effects. Econometrica, 49(6), 1417-1426.

Oikarinen, E. and Engblom, J. (2016). Differences in housing price dynamics across cities: a comparison of different panel model specifications. Urban Studies, 53(11), 2312-2329.

Paciorek, A. (2013). Supply constraints and housing market dynamics. Journal of Urban Economics, 77, 11-26.

Pedroni, P. (2000). Fully modified OLS for heterogeneous cointegrated panels. In: B. H. Baltagi (Editor), Nonstationary Panels, Cointegration in Panels and Dynamic Panels, Amsterdam: Elsevier.

Pedroni, P. (2001). Purchasing power parity tests in cointegrated panels. Review of Economics and Statistics, 83(4), 727-731.

Pedroni, P. (2007). Social capital, barriers to production and capital shares: implications for the importance of parameter heterogeneity from a nonstationary panel approach. Journal of Applied Econometrics, 22(2), 429-451.

Pesaran, M. H. (2004). General diagnostic tests for cross section dependence in panels. CESifo Working Paper No. 1229.

Pesaran, M. H. (2006). Estimation and inference in large heterogeneous panels with a multifactor error structure. Econometrica, 74(4), 967-1012.

Pesaran, M. H. (2007). A simple panel unit root test in the presence of cross-section dependence. Journal of Applied Econometrics, 22(2), 265-312. 
Pesaran, M. H., Shin, Y. and Smith, R. P. (1999). Pooled mean group estimation of dynamic heterogeneous panels. Journal of the American Statistical Association, 94(446), 621-634.

Pesaran, M. H. and Smith, R. P. (1995). Estimating long-run relationships from dynamic heterogeneous panels. Journal of Econometrics, 68(1), 79-113.

Pesaran, M. H. and Yamagata, T. (2008). Testing slope homogeneity in large panels. Journal of Econometrics, 142(1), 50-93.

Piazzesi, M. and Schneider, M. (2016). Housing and macroeconomics. In: Taylor, J. B. and Uhlig, H. (Editors), Handbook of Macroeconomics, 2B, Amsterdam: Elsevier, 1547-1640.

Røed Larsen, E. and Weum, S. (2008). Testing the efficiency of the Norwegian housing market. Journal of Urban Economics, 64(2), 510-517.

Sadorsky, P. (2013). Do urbanization and industrialization affect energy intensity in developing countries? Energy Econemics, 37, 5259.

Saiz, A. (2010). The geographic determinants of housing supply. The Quarterly Journal of Economics, 125(3), 1253-1296.

Saks, R. E. (2008). Job creation and housing construction: constraints on metropolitan area employment growth. Journal of Urban Economics, 64(1), 178-195.

Saldías, M. (2013). A market-based approach to sector risk determinants and transmission in the euro area. Journal of Banking and Finance, 37(11), 4534-4555.

Van Nieuwerburgh, S. and Weill, P. (2010). Why has house price dispersion gone up? Review of Economic Studies, 77(4), 1567-1606. 
Table 1. Summary statistics

\begin{tabular}{|c|c|c|c|c|}
\hline Variable & $\begin{array}{l}\text { Mean across } \\
\text { all MSAs }\end{array}$ & $\begin{array}{l}\text { Standard } \\
\text { deviation of } \\
\text { MSA-specific } \\
\text { means }\end{array}$ & $\begin{array}{l}\text { Smallest } \\
\text { mean across } \\
\text { MSAs }\end{array}$ & $\begin{array}{l}\text { Largest mean } \\
\text { across MSAs }\end{array}$ \\
\hline Real house price growth $(\Delta p)$ & 0.002 & 0.002 & -0.002 & 0.008 \\
\hline Real aggregate income growth $(\Delta y)$ & 0.006 & 0.002 & -0.001 & 0.013 \\
\hline Real construction cost growth $(\Delta c)$ & 0.001 & 0.001 & 0.000 & 0.003 \\
\hline Real interest rate $(r)$ & 0.074 & 0.000 & 0.074 & 0.074 \\
\hline Real interest rate change $(\Delta r)$ & -0.000 & 0.000 & -0.000 & -0.000 \\
\hline Equality tests (p-values) & $\begin{array}{l}\text { Equality of } \\
\text { means }\end{array}$ & $\begin{array}{l}\text { Equality of } \\
\text { variances }\end{array}$ & $\begin{array}{l}\text { Equality of } \\
\text { smallest and } \\
\text { largest means }\end{array}$ & \\
\hline$\Delta p$ & 0.235 & $0.000^{* * *}$ & $0.005^{* * *}$ & \\
\hline$\Delta y$ & $0.000^{* * *}$ & $0.000^{* * *}$ & $0.000^{* * *}$ & \\
\hline$\Delta c$ & 1.000 & 1.000 & 0.103 & \\
\hline Correlations $^{\mathrm{a}}$ & $\Delta p$ & $\Delta y$ & $\Delta c$ & $\Delta r$ \\
\hline$\Delta p$ & 1.000 & & & \\
\hline$\Delta y$ & $0.330^{* * *}$ & 1.000 & & \\
\hline$\Delta c$ & $0.304^{* * *}$ & $0.218^{* * *}$ & 1.000 & \\
\hline$\Delta r$ & $0.125^{* * *}$ & $0.185^{* * *}$ & $0.531^{* * *}$ & 1.000 \\
\hline \multicolumn{5}{|l|}{ Correlations between MSAs ${ }^{\mathrm{b}}$} \\
\hline$\Delta p$ & $0.439^{* * *}$ & & & \\
\hline$\Delta y$ & $0.759^{* * *}$ & & & \\
\hline$\Delta c$ & $0.907^{* * *}$ & & & \\
\hline \multicolumn{5}{|c|}{$\begin{array}{l}\text { The sample period is } 1980 \mathrm{Q} 1-2015 \mathrm{Q} 2 .^{*},{ }^{* *} \text { and }{ }^{* * *} \text { denote statistical significance at the } 10 \%, 5 \% \text {, and } 1 \% \\
\text { level, respectively. Equality of means is tested by the Welch F-test. Null hypothesis in "Equality of means" } \\
=\text { equal means across MSAs. Null hypothesis in "Equality of smallest and largest means" = equal means in } \\
\text { the cities with highest and lowest mean growth rates. Equality of variances is tested by the Brown-Forsythe } \\
\text { test, where the null hypothesis = equal variances across MSAs }{ }^{\text {a }} \text { Correlations for all of the data, i.e., all } \\
\text { MSAs stacked together. "Means of quarterly between MSA correlations; statistical significances based on } \\
\text { the Pesaran (2004) CD test. }\end{array}$} \\
\hline
\end{tabular}


Table 2. Unit root test statistics

\begin{tabular}{|c|c|c|c|c|c|}
\hline & O lags & 1 lag & 2 lags & 3 lags & 4 lags \\
\hline \multicolumn{6}{|c|}{ CIPS panel unit root test statistics $\left(H_{0}=\right.$ non-stationarity) } \\
\hline \multicolumn{6}{|c|}{ With a linear trend } \\
\hline$p_{i t}$ & -1.542 & -1.687 & -1.873 & -2.178 & -2.461 \\
\hline$y_{i t}$ & -0.946 & -1.887 & -2.206 & -2.307 & -2.135 \\
\hline$c_{i t}$ & $-2.674^{* * *}$ & $-2.554^{*}$ & -2.521 & -2.188 & -2.108 \\
\hline$r_{t}^{a}$ & $-5.214^{* * *}$ & $-4.480^{* * *}$ & $-3.499^{* *}$ & $-3.279^{*}$ & $-3.336^{*}$ \\
\hline \multicolumn{6}{|c|}{ Without a linear trend } \\
\hline$p_{i t}$ & -1.640 & -1.743 & -1.841 & -2.009 & -2.029 \\
\hline$y_{i t}$ & -0.828 & -1.809 & $-2.143^{* *}$ & $-2.208^{* *}$ & $-2.051^{*}$ \\
\hline$c_{i t}$ & -1.792 & -1.607 & -1.718 & -1.506 & -1.432 \\
\hline$r_{t}^{a}$ & -1.601 & -1.359 & -0.949 & -1.101 & -1.191 \\
\hline$\Delta p_{i t}$ & $-39.82^{* * *}$ & $-33.70^{* * *}$ & $-24.71^{* * *}$ & $-17.92^{* * *}$ & $-14.50^{* * *}$ \\
\hline$\Delta y_{i t}$ & $-34.07^{* * * *}$ & $-22.47^{* * * *}$ & $-17.83^{* * *}$ & $-19.97^{* * * *}$ & $-14.47^{* * *}$ \\
\hline$\Delta c_{i t}$ & $-40.50^{* * * *}$ & $-38.04^{* * *}$ & $-35.67^{* * *}$ & $-30.01^{* * * *}$ & $-24.69^{* * *}$ \\
\hline$\Delta r_{t}^{a}$ & $-13.87^{* * * *}$ & $-12.00^{* * *}$ & $-8.710^{* * *}$ & $-6.829^{* * *}$ & $-5.672^{* * *}$ \\
\hline \multicolumn{6}{|c|}{ Average residual cross-correlation of $A D F$ regressions ${ }^{b}$} \\
\hline$p_{i t}$ & 0.390 & 0.414 & 0.456 & 0.449 & 0.418 \\
\hline$y_{i t}$ & 0.423 & 0.748 & 0.7530 & 0.734 & 0.699 \\
\hline$c_{i t}$ & 0.943 & 0.907 & 0.893 & 0.891 & 0.887 \\
\hline$\Delta p_{i t}$ & 0.406 & 0.453 & 0.450 & 0.428 & 0.442 \\
\hline$\Delta y_{i t}$ & 0.577 & 0.797 & 0.800 & 0.787 & 0.788 \\
\hline$\Delta c_{i t}$ & 0.877 & 0.895 & 0.894 & 0.888 & 0.877 \\
\hline
\end{tabular}

The regression specifications follow those in Holly et al. (2010). An intercept is included in all the regressions. The number of lags refers to lag lengths in the CADF equations. ${ }^{*},{ }^{* * *}$, and ${ }^{* * *}$ denote statistical significance at the $10 \%, 5 \%$, and $1 \%$ level, respectively, in the unit root tests. ${ }^{a}$ Conventional ADF test. ${ }^{b}$ With a linear trend for the levels and without a trend for the differences; all reported crosssectional correlations are significant at the $1 \%$ level in the Pesaran (2004) CD test. 
Table 3. Mean-group estimation methods

\begin{tabular}{|c|c|c|}
\hline Method/Estimator & Characteristics & Source \\
\hline Mean Group (MG) & $\begin{array}{l}\text { Allows for spatial heterogeneity and nonstationary, but } \\
\text { cointegrated, data }\end{array}$ & $\begin{array}{l}\text { Pesaran and Smith } \\
\text { (1995) }\end{array}$ \\
\hline $\begin{array}{l}\text { Fully Modified OLS Mean } \\
\text { Group (FMOLS-MG) }\end{array}$ & $\begin{array}{l}\text { Controls for endogeneity in addition to the characteristics } \\
\text { of MG }\end{array}$ & Pedroni $(2000,2001)$ \\
\hline $\begin{array}{l}\text { Fully Modified OLS } \\
\text { Augmented Mean Group } \\
\text { (FMOLS-AMG) }\end{array}$ & $\begin{array}{l}\text { Controls for cross-sectional dependence in addition to the } \\
\text { characteristics of FMOLS-MG }\end{array}$ & $\begin{array}{l}\text { Eberhardt and Teal } \\
\text { (2010) }\end{array}$ \\
\hline $\begin{array}{l}\text { Common Correlated Effects } \\
\text { Mean Group (CCEMG) }\end{array}$ & $\begin{array}{l}\text { Controls for cross-sectional dependence in addition to the } \\
\text { characteristics of MG }\end{array}$ & Pesaran (2006) \\
\hline $\begin{array}{l}\text { Dynamic CCEMG } \\
\text { (DCCEMG) }\end{array}$ & $\begin{array}{l}\text { Allows for lagged dependent variables, addressing the } \\
\text { Nickell bias, in addition to the characteristics of CCEMG }\end{array}$ & $\begin{array}{l}\text { Chudik and Pesaran } \\
(2015)\end{array}$ \\
\hline
\end{tabular}


Table 4. Estimation results for the long-run equation

\begin{tabular}{|c|c|c|c|c|c|}
\hline & $\begin{array}{l}{[1]} \\
\text { MG }\end{array}$ & $\begin{array}{c}{[2]} \\
\text { FMOLS-MG }\end{array}$ & $\begin{array}{c}{[3]} \\
\text { FMOLS-AMG }\end{array}$ & $\begin{array}{c}\text { [4] } \\
\text { CCEMG }\end{array}$ & $\begin{array}{c}\text { [5] } \\
\text { DCCEMG }\end{array}$ \\
\hline \multicolumn{6}{|c|}{ Mean-Group estimates (standard errors in parentheses) } \\
\hline$y_{i t}$ & $\begin{array}{l}0.694^{* * *} \\
(0.057)\end{array}$ & $\begin{array}{c}0.702^{* * * *} \\
(0.029)\end{array}$ & $\begin{array}{c}0.807^{* * * *} \\
(0.017)\end{array}$ & $\begin{array}{l}1.637^{* * * *} \\
(0.135)\end{array}$ & $\begin{array}{l}1.518^{* * * *} \\
(0.139)\end{array}$ \\
\hline$c_{i t}$ & $\begin{array}{c}0.200^{* * * *} \\
(0.064)\end{array}$ & $\begin{array}{c}0.068^{*} \\
(0.040)\end{array}$ & $\begin{array}{l}0.072^{* * * * *} \\
(0.023)\end{array}$ & $\begin{array}{l}1.271^{* * * *} \\
(0.282)\end{array}$ & $\begin{array}{l}1.077^{* * * *} \\
(0.296)\end{array}$ \\
\hline$r_{i t}$ & $\begin{array}{c}2.060^{* * *} \\
(0.244)\end{array}$ & $\begin{array}{c}2.603^{* * * *} \\
(0.208)\end{array}$ & $\begin{array}{l}-0.096 \\
(0.115)\end{array}$ & $\begin{array}{c}0.192 \\
(0.167)\end{array}$ & $\begin{array}{c}0.103 \\
(0.172)\end{array}$ \\
\hline \multicolumn{6}{|c|}{ CIPS unit root test statistics } \\
\hline 1 lag & $-2.549^{* * * *}$ & -1.693 & $-2.066^{* *}$ & -1.894 & -1.809 \\
\hline 2 lags & $-2.429^{* * *}$ & -1.710 & $-2.094^{* *}$ & -1.795 & -1.503 \\
\hline 3 lags & $-2.634^{* * *}$ & -1.881 & $-2.384^{* * * *}$ & -1.866 & -1.499 \\
\hline 4 lags & $-2.891^{* * *}$ & $-2.012^{*}$ & $-2.601^{* * *}$ & -1.989 & -1.658 \\
\hline $\begin{array}{l}\text { Swamy test of } \\
\text { slope homogeneity } \\
\text { (p-value) }\end{array}$ & $0.000^{* * * *}$ & & & $0.000^{* * *}$ & $0.000^{* * *}$ \\
\hline $\begin{array}{l}\text { F-test of slope } \\
\text { homogeneity } \\
\text { (p-value) }\end{array}$ & & $0.000^{* * * *}$ & $0.000^{* * * *}$ & & \\
\hline $\begin{array}{l}\text { Average cross- } \\
\text { correlation } \\
\text { (CD-test, p-value) }\end{array}$ & $\begin{array}{c}0.591^{* * * *} \\
(0.000)\end{array}$ & $\begin{array}{c}0.341^{* * * *} \\
(0.000)\end{array}$ & $\begin{array}{c}0.001 \\
(0.535)\end{array}$ & $\begin{array}{c}0.012^{* * *} \\
(0.000)\end{array}$ & $\begin{array}{c}0.007^{* * * *} \\
(0.000)\end{array}$ \\
\hline
\end{tabular}

Dependent variable $=p_{i t} .{ }^{* * *}$, and ${ }^{* * * *}$ denote statistical significance at the $10 \%, 5 \%$, and $1 \%$ level, respectively. The null hypothesis in the Swamy test and F-test is that of homogenous slope coefficients across MSAs. Following Holly et al. (2010), the CIPS statistics are based on regressions that include MSA-specific intercepts. With $\mathrm{N}=70$ and $\mathrm{T}=$ 141 , the $10 \%, 5 \%$, and $1 \%$ critical values in the CIPS test are $-2.01,-2.06$, and -2.14 , respectively. The FMOLS estimations are based on the Bartlett kernel with Andrews automatic bandwidth selection method. The bandwidth selection method choice does not notably affect the results. The selected lag length for cross-sectional means in the DCCEMG estimation is four. The lag length does not notably affect the results. 
Table 5. Estimation results for short-term dynamics

\begin{tabular}{|c|c|c|c|c|c|}
\hline & $\begin{array}{l}{[1]} \\
\text { OLS }\end{array}$ & $\begin{array}{l}{[2]} \\
\mathbf{R E}\end{array}$ & $\begin{array}{l}{[3]} \\
\text { MG }\end{array}$ & $\begin{array}{c}{[4]} \\
\text { CCEMG }\end{array}$ & $\begin{array}{c}{[5]} \\
\text { DCCEMG }\end{array}$ \\
\hline$\Delta p_{i, t-1}$ & $\begin{array}{l}0.278^{* * *} \\
(0.010)\end{array}$ & $\begin{array}{l}0.261^{* * *} \\
(0.035)\end{array}$ & $\begin{array}{l}0.255^{* * *} \\
(0.035)\end{array}$ & $\begin{array}{l}0.123^{* * *} \\
(0.036)\end{array}$ & $\begin{array}{l}0.173^{* * *} \\
(0.035)\end{array}$ \\
\hline$\Delta y_{i, t-1}$ & $\begin{array}{l}0.130^{* * * *} \\
(0.024)\end{array}$ & $\begin{array}{c}0.107^{* * *} \\
(0.031)\end{array}$ & $\begin{array}{l}0.095^{* * *} \\
(0.032)\end{array}$ & $\begin{array}{l}0.560^{* * * *} \\
(0.072)\end{array}$ & $\begin{array}{l}0.484^{* * * *} \\
(0.066)\end{array}$ \\
\hline$\Delta c_{i, t-1}$ & $\begin{array}{l}0.053^{*} \\
(0.023)\end{array}$ & $\begin{array}{c}0.042 \\
(0.040)\end{array}$ & $\begin{array}{c}0.042 \\
(0.033)\end{array}$ & $\begin{array}{c}0.101 \\
(0.071)\end{array}$ & $\begin{array}{l}0.243^{* *} \\
(0.080)\end{array}$ \\
\hline$\Delta r_{i, t-1}$ & $\begin{array}{c}0.144^{* * *} \\
(0.029)\end{array}$ & $\begin{array}{c}0.155^{* * *} \\
(0.032)\end{array}$ & $\begin{array}{c}0.157^{* * * *} \\
(0.028)\end{array}$ & $\begin{array}{l}-0.001 \\
(0.029)\end{array}$ & $\begin{array}{c}0.003 \\
(0.005)\end{array}$ \\
\hline$\left(p-p^{*}\right)_{i, t-1}$ & $\begin{array}{l}-0.020^{* * *} \\
(0.002)\end{array}$ & $\begin{array}{l}-0.029^{* * *} \\
(0.003)\end{array}$ & $\begin{array}{l}-0.032^{* * *} \\
(0.005)\end{array}$ & $\begin{array}{l}-0.046^{* * *} \\
(0.005)\end{array}$ & $\begin{array}{l}-0.046^{* * *} \\
(0.005)\end{array}$ \\
\hline $\mathrm{R}^{2}$ & 0.121 & 0.218 & 0.234 & 0.612 & 0.724 \\
\hline $\begin{array}{l}\text { Swamy test of slope homogeneity } \\
\text { (p-value) }\end{array}$ & & & $0.000^{* * *}$ & $0.000^{* * *}$ & $0.000^{* * *}$ \\
\hline $\begin{array}{l}\text { Average cross-correlation } \\
\text { (CD-test, p-value) }\end{array}$ & $\begin{array}{l}0.415^{* * *} \\
(0.000) \\
\end{array}$ & $\begin{array}{l}0.426^{* * *} \\
(0.000)\end{array}$ & $\begin{array}{l}0.425^{* * *} \\
(0.000)\end{array}$ & $\begin{array}{c}-0.005^{* * *} \\
(0.001)\end{array}$ & $\begin{array}{l}-0.003^{*} \\
(0.088)\end{array}$ \\
\hline
\end{tabular}

Dependent variable $=\Delta p_{i, t}$. Standard errors in parentheses. ${ }^{*},{ }^{* *}$, and ${ }^{* * *}$ denote statistical significance at the $10 \%$, $5 \%$, and $1 \%$ level, respectively. We also tested for the need for seasonal dummies in the models and found that such dummies are not needed. The null hypothesis in the Swamy test is that of homogenous slope coefficients across MSAs. 
Table 6. Income elasticity of price, price elasticity of supply, maximum overvaluation and duration of bubble during the 2000s, and population rank in 2015

\begin{tabular}{|c|c|c|c|c|c|}
\hline MSA & $\begin{array}{c}\text { Income } \\
\text { elasticity } \\
\text { of price }\end{array}$ & $\begin{array}{c}\text { Price } \\
\text { elasticity of } \\
\text { supply } \\
\end{array}$ & $\begin{array}{c}\begin{array}{c}\text { Maximum } \\
\text { overvaluation } \\
(\%)\end{array} \\
\end{array}$ & $\begin{array}{c}\text { Bubble } \\
\text { duration } \\
\text { (quarters) }\end{array}$ & $\begin{array}{l}\text { Population } \\
\text { rank }\end{array}$ \\
\hline \multicolumn{6}{|c|}{ MSAs with smaller than average supply elasticity and $>20 \%$ overvaluation during the 2000 s } \\
\hline Detroit-Dearborn-Livonia, MI (MSAD) & 2.73 & 1.24 & 32 & 26 & 38 \\
\hline Los Angeles-Long Beach-Glendale, CA (MSAD) & 1.64 & 0.63 & 56 & 17 & 2 \\
\hline Miami-Miami Beach-Kendall, FL (MSAD) & 1.32 & 0.60 & 59 & 17 & 18 \\
\hline Providence-Warwick, RI-MA & 1.24 & 1.61 & 46 & 18 & 41 \\
\hline Chicago-Naperville-Arlington Heights, IL (MSAD) & 1.21 & 0.81 & 26 & 12 & 3 \\
\hline Philadelphia, PA (MSAD) & 1.20 & 1.65 & 30 & 10 & 28 \\
\hline Boston, MA (MSAD) & 1.17 & 0.60 & 40 & 19 & 35 \\
\hline $\begin{array}{l}\text { San Francisco-Redwood City-South San Francisco, } \\
\text { CA (MSAD) }\end{array}$ & 1.13 & 0.66 & 42 & 21 & 40 \\
\hline Worcester, MA-CT & 1.11 & 0.86 & 41 & 19 & 62 \\
\hline New Haven-Milford, CT & 1.09 & 0.98 & 31 & 15 & 68 \\
\hline Tacoma-Lakewood, WA (MSAD) & 1.08 & 1.21 & 31 & 11 & 70 \\
\hline $\begin{array}{l}\text { Fort Lauderdale-Pompano Beach-Deerfield Beach, } \\
\text { FL (MSAD) }\end{array}$ & 1.06 & 0.65 & 61 & 18 & 36 \\
\hline Oxnard-Thousand Oaks-Ventura, CA & 1.06 & 0.75 & 55 & 17 & 69 \\
\hline Seattle-Bellevue-Everett, WA (MSAD) & 1.04 & 0.88 & 24 & 8 & 14 \\
\hline San Diego-Carlsbad, CA & 1.04 & 0.67 & 53 & 18 & 11 \\
\hline Minneapolis-St. Paul-Bloomington, MN-WI & 0.96 & 1.45 & 31 & 15 & 10 \\
\hline Camden, NJ (MSAD) & 0.95 & 1.65 & 30 & 12 & 50 \\
\hline Tampa-St. Petersburg-Clearwater, FL & 0.94 & 1.00 & 54 & 17 & 13 \\
\hline Hartford-West Hartford-East Hartford, CT & 0.87 & 1.50 & 22 & 7 & 51 \\
\hline Baltimore-Columbia-Towson, MD & 0.87 & 1.23 & 32 & 13 & 17 \\
\hline $\begin{array}{l}\text { New York-Jersey City-White Plains, NY-NJ } \\
\text { (MSAD) }\end{array}$ & 0.84 & 0.76 & 43 & 19 & 1 \\
\hline Jacksonville, FL & 0.82 & 1.06 & 42 & 18 & 43 \\
\hline Tucson, AZ & 0.79 & 1.42 & 39 & 12 & 57 \\
\hline Riverside-San Bernardino-Ontario, CA & 0.72 & 0.94 & 70 & 19 & 9 \\
\hline Phoenix-Mesa-Scottsdale, AZ & 0.71 & 1.61 & 49 & 14 & 8 \\
\hline Virginia Beach-Norfolk-Newport News, VA-NC & 0.71 & 0.82 & 25 & 11 & 39 \\
\hline $\begin{array}{l}\text { Washington-Arlington-Alexandria, DC-VA-MD- } \\
\text { WV (MSAD) }\end{array}$ & 0.70 & 1.61 & 42 & 15 & 6 \\
\hline Newark, NJ-PA (MSAD) & 0.70 & 1.16 & 36 & 15 & 19 \\
\hline Orlando-Kissimmee-Sanford, FL & 0.62 & 1.12 & 59 & 20 & 23 \\
\hline Bakersfield, CA & 0.61 & 1.64 & 74 & 18 & 65 \\
\hline Bridgeport-Stamford-Norwalk, CT & 0.48 & 0.98 & 42 & 19 & 61 \\
\hline Las Vegas-Henderson-Paradise, NV & 0.37 & 1.39 & 65 & 17 & 29 \\
\hline
\end{tabular}




\begin{tabular}{|c|c|c|c|c|c|}
\hline MSA & $\begin{array}{c}\text { Income } \\
\text { elasticity } \\
\text { of price } \\
\end{array}$ & $\begin{array}{c}\text { Price } \\
\text { elasticity of } \\
\text { supply } \\
\end{array}$ & $\begin{array}{c}\text { Maximum } \\
\text { overvaluation } \\
(\%)\end{array}$ & $\begin{array}{c}\text { Bubble } \\
\text { duration } \\
\text { (quarters) }\end{array}$ & $\begin{array}{c}\text { Population } \\
\text { rank }\end{array}$ \\
\hline \multicolumn{6}{|c|}{ MSAs with larger than average supply elasticity and $>20 \%$ overvaluation during the $2000 \mathrm{~s}$} \\
\hline Fresno, CA & 0.90 & 1.84 & 70 & 19 & 60 \\
\hline Lake County-Kenosha County, IL-WI (MSAD) & 0.76 & 1.75 & 22 & 6 & 67 \\
\hline Allentown-Bethlehem-Easton, PA-NJ & 0.29 & 1.86 & 24 & 7 & 71 \\
\hline \multicolumn{6}{|c|}{ MSAs with smaller than average supply elasticity and no overvaluation $>20 \%$ during the 2000 s } \\
\hline New Orleans-Metairie, LA & 1.35 & 0.81 & 14 & 0 & 49 \\
\hline Portland-Vancouver-Hillsboro, OR-WA & 1.32 & 1.07 & 20 & 0 & 22 \\
\hline Milwaukee-Waukesha-West Allis, WI & 1.18 & 1.03 & 15 & 0 & 42 \\
\hline Salt Lake City, UT & 1.14 & 0.75 & 9 & 0 & 52 \\
\hline Cleveland-Elyria, $\mathrm{OH}$ & 1.09 & 1.02 & 17 & 0 & 31 \\
\hline Denver-Aurora-Lakewood, CO & 0.94 & 1.53 & 12 & 0 & 15 \\
\hline Pittsburgh, PA & 0.69 & 1.20 & 3 & 0 & 25 \\
\hline Rochester, NY & 0.42 & 1.40 & 1 & 0 & 55 \\
\hline \multicolumn{6}{|c|}{ MSAs with larger than average supply elasticity and no overvaluation $>20 \%$ during the 2000 s } \\
\hline Louisville/Jefferson County, KY-IN & 0.91 & 2.34 & 7 & 0 & 46 \\
\hline Albany-Schenectady-Troy, NY & 0.86 & 1.70 & 12 & 0 & 66 \\
\hline Buffalo-Cheektowaga-Niagara Falls, NY & 0.86 & 1.83 & 1 & 0 & 54 \\
\hline Grand Rapids-Wyoming, MI & 0.70 & 2.39 & 14 & 0 & 56 \\
\hline St. Louis, MO-IL & 0.67 & 2.36 & 12 & 0 & 16 \\
\hline Cincinnati, OH-KY-IN & 0.62 & 2.46 & 9 & 0 & 27 \\
\hline Columbus, $\mathrm{OH}$ & 0.61 & 2.71 & 9 & 0 & 32 \\
\hline Birmingham-Hoover, AL & 0.60 & 2.14 & 5 & 0 & 53 \\
\hline Omaha-Council Bluffs, NE-IA & 0.59 & 3.47 & 7 & 0 & 63 \\
\hline Richmond, VA & 0.57 & 2.60 & 18 & 0 & 48 \\
\hline Kansas City, MO-KS & 0.55 & 3.19 & 14 & 0 & 30 \\
\hline Albuquerque, NM & 0.55 & 2.11 & 8 & 0 & 64 \\
\hline Oklahoma City, OK & 0.53 & 3.29 & 2 & 0 & 44 \\
\hline Nashville-Davidson--Murfreesboro--Franklin, TN & 0.50 & 2.24 & 4 & 0 & 37 \\
\hline Atlanta-Sandy Springs-Roswell, GA & 0.46 & 2.55 & 12 & 0 & 5 \\
\hline Indianapolis-Carmel-Anderson, IN & 0.44 & 4.00 & 7 & 0 & 34 \\
\hline Austin-Round Rock, TX & 0.44 & 3.00 & 2 & 0 & 33 \\
\hline Houston-The Woodlands-Sugar Land, TX & 0.41 & 2.30 & 3 & 0 & 4 \\
\hline Tulsa, OK & 0.38 & 3.35 & 16 & 0 & 59 \\
\hline Charlotte-Concord-Gastonia, NC-SC & 0.37 & 3.09 & 11 & 0 & 20 \\
\hline Memphis, TN-MS-AR & 0.32 & 1.76 & 3 & 0 & 45 \\
\hline Raleigh, NC & 0.26 & 2.11 & 1 & 0 & 47 \\
\hline San Antonio-New Braunfels, TX & 0.23 & 2.98 & 2 & 0 & 24 \\
\hline Dallas-Plano-Irving, TX (MSAD) & 0.13 & 2.18 & 2 & 0 & 7 \\
\hline Fort Worth-Arlington, TX (MSAD) & 0.05 & 2.80 & 2 & 0 & 21 \\
\hline \multicolumn{6}{|c|}{ Supply elasticity value missing } \\
\hline Anaheim-Santa Ana-Irvine, CA (MSAD) & 1.12 & & 46 & 16 & 12 \\
\hline Sacramento--Roseville--Arden-Arcade, CA & 0.88 & & 64 & 18 & 26 \\
\hline
\end{tabular}

Price elasticities of supply are from Saiz (2010 and personal correspondence). 
Table 7. Cross-sectional OLS regressions for bubble size and duration in the 2000s

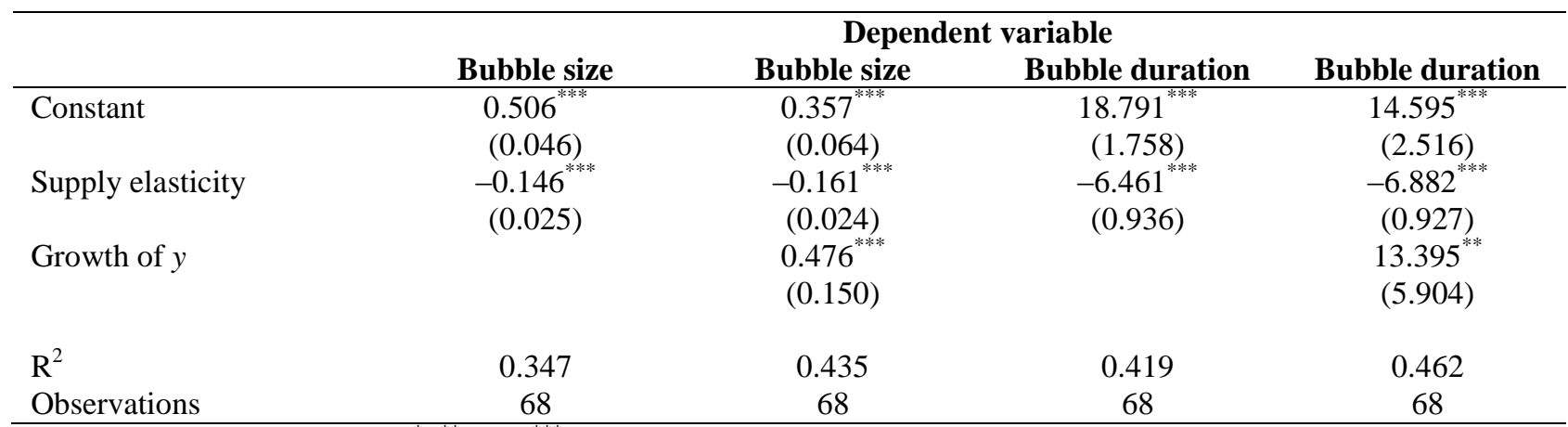

Standard errors in parenthesis. ${ }^{*},{ }^{* *}$, and ${ }^{* * *}$ denote statistical significance at the $10 \%, 5 \%$, and $1 \%$ level, respectively. Duration is the number of continuous quarters during which at least $20 \%$ overvaluation is observed. Estimations exclude Anaheim and Sacramento due to missing supply elasticities. 
Figure 1. Long-term income elasticity frequency distribution

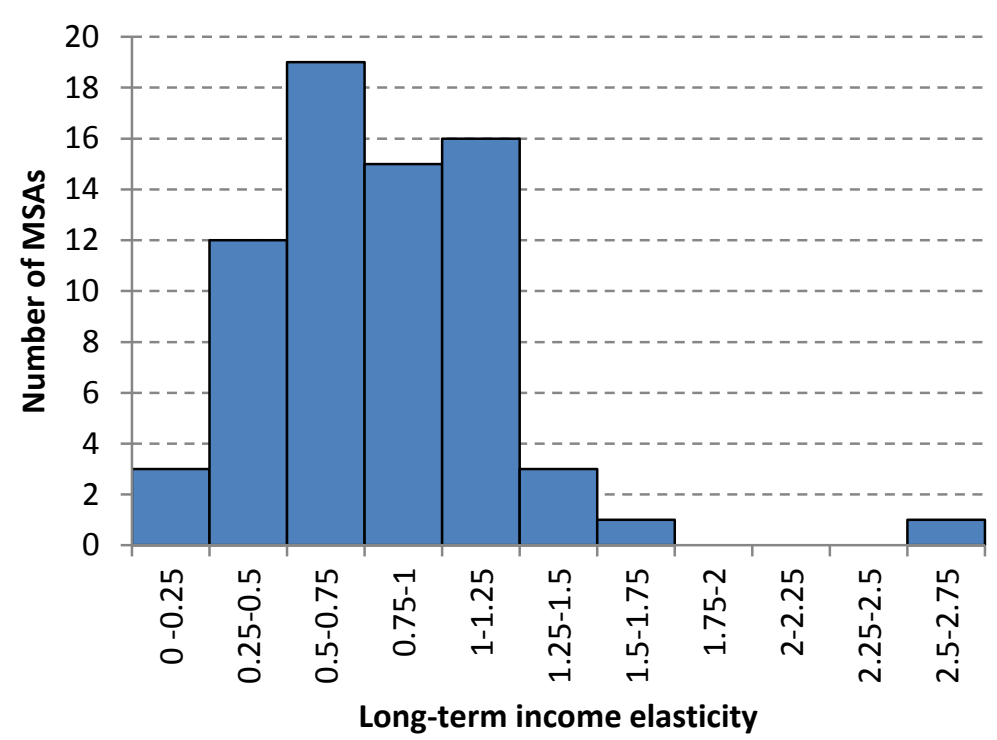


Figure 2. Geographic distribution of long-run income elasticities (IN COLOR)

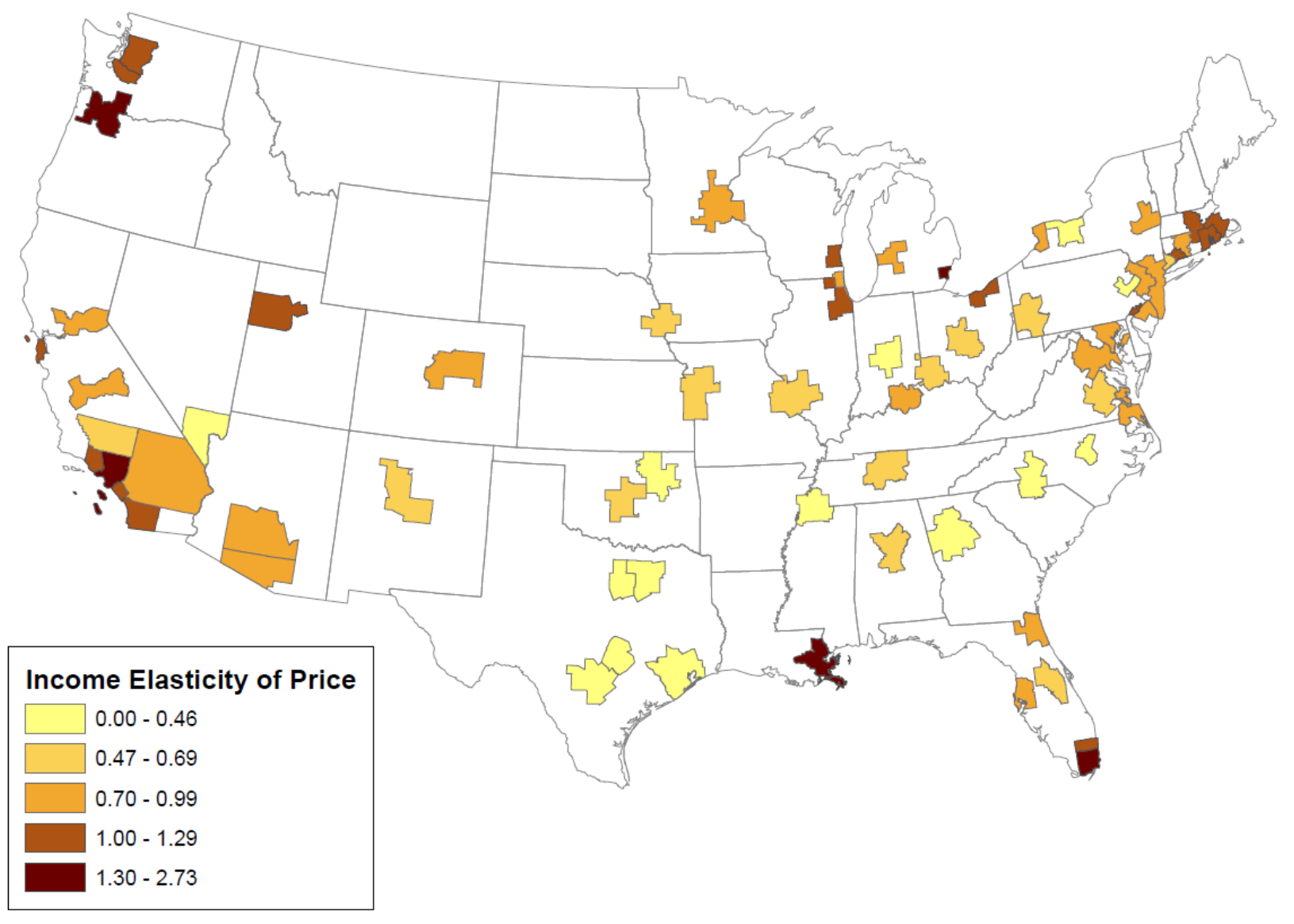


Figure 3. Relationship between income elasticity of house prices and price elasticity of housing supply

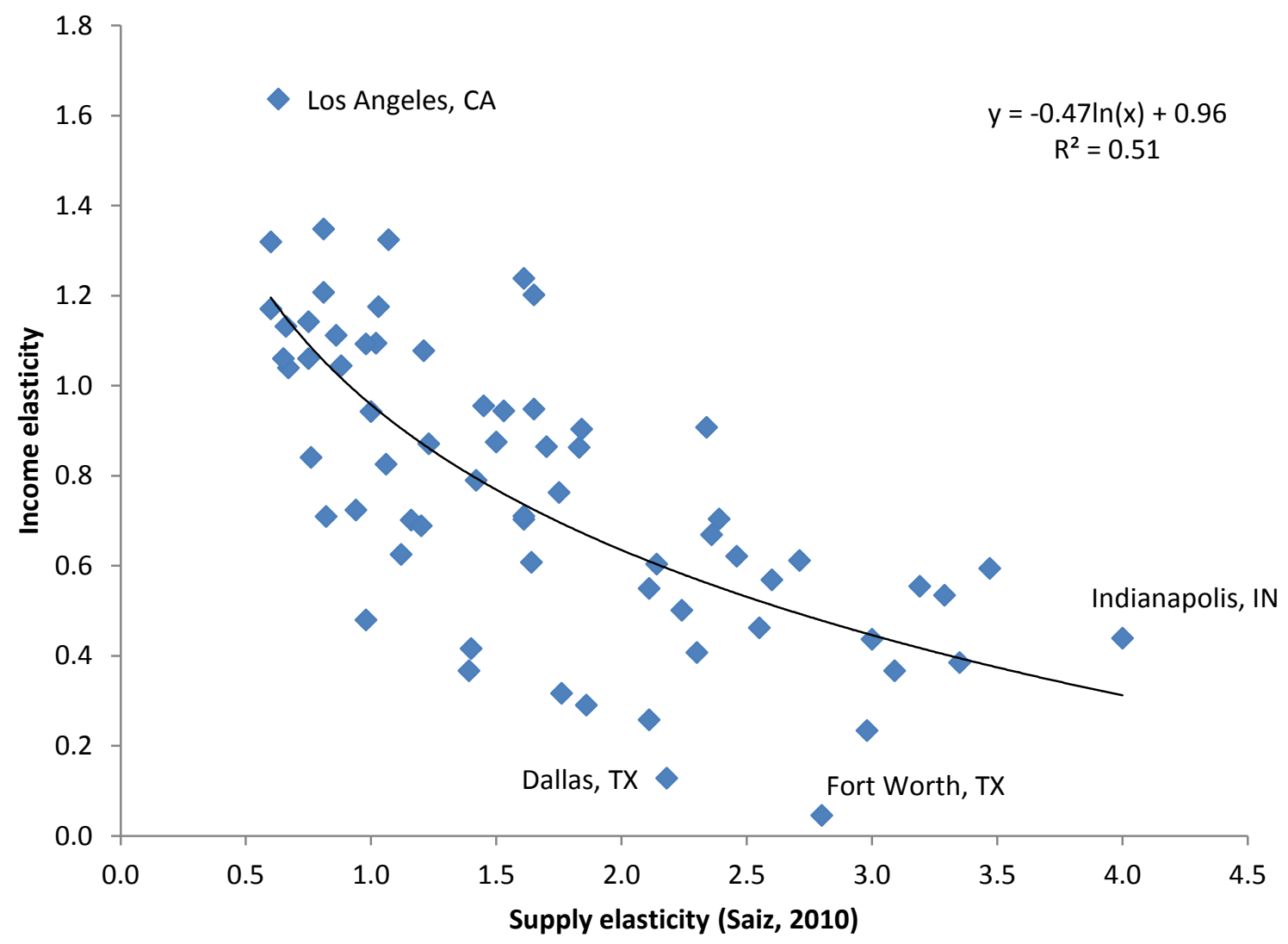

Excludes Detroit (income elasticity $=2.73$ ). 
Figure 4. Short-run momentum and reversion parameter frequency distributions
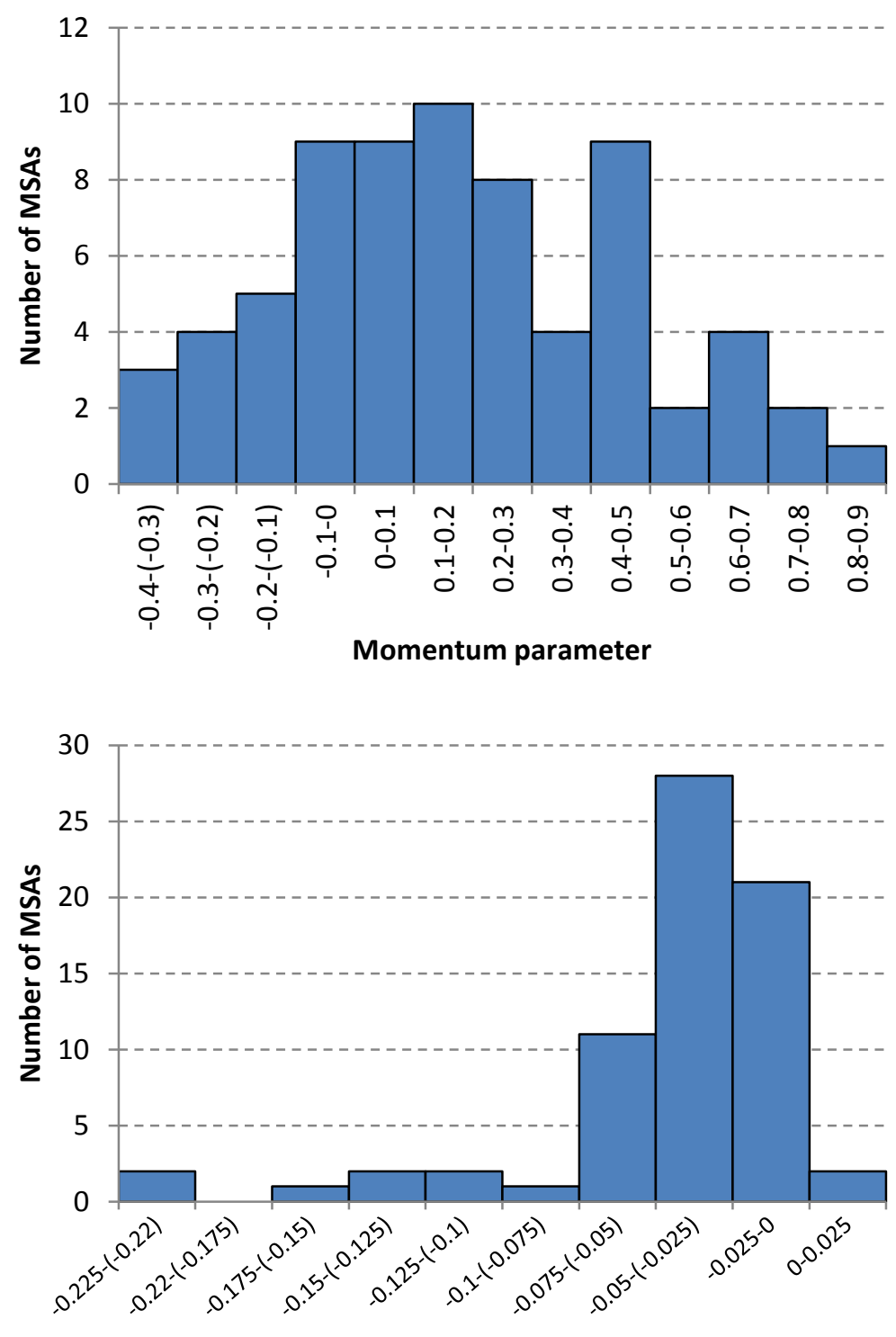

Reversion parameter 
Figure 5. House price deviations from the long-term fundamental level (IN COLOR)
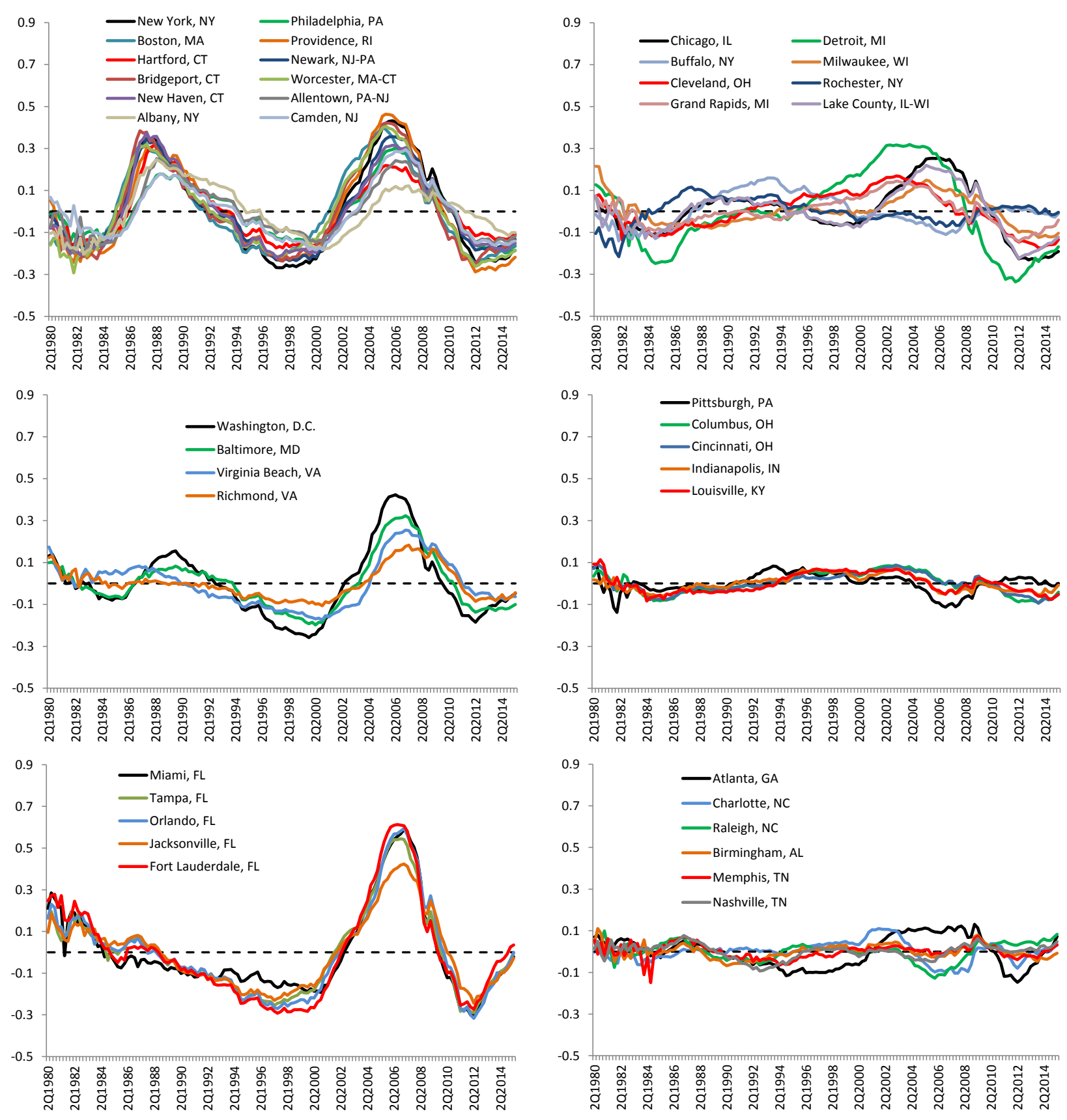

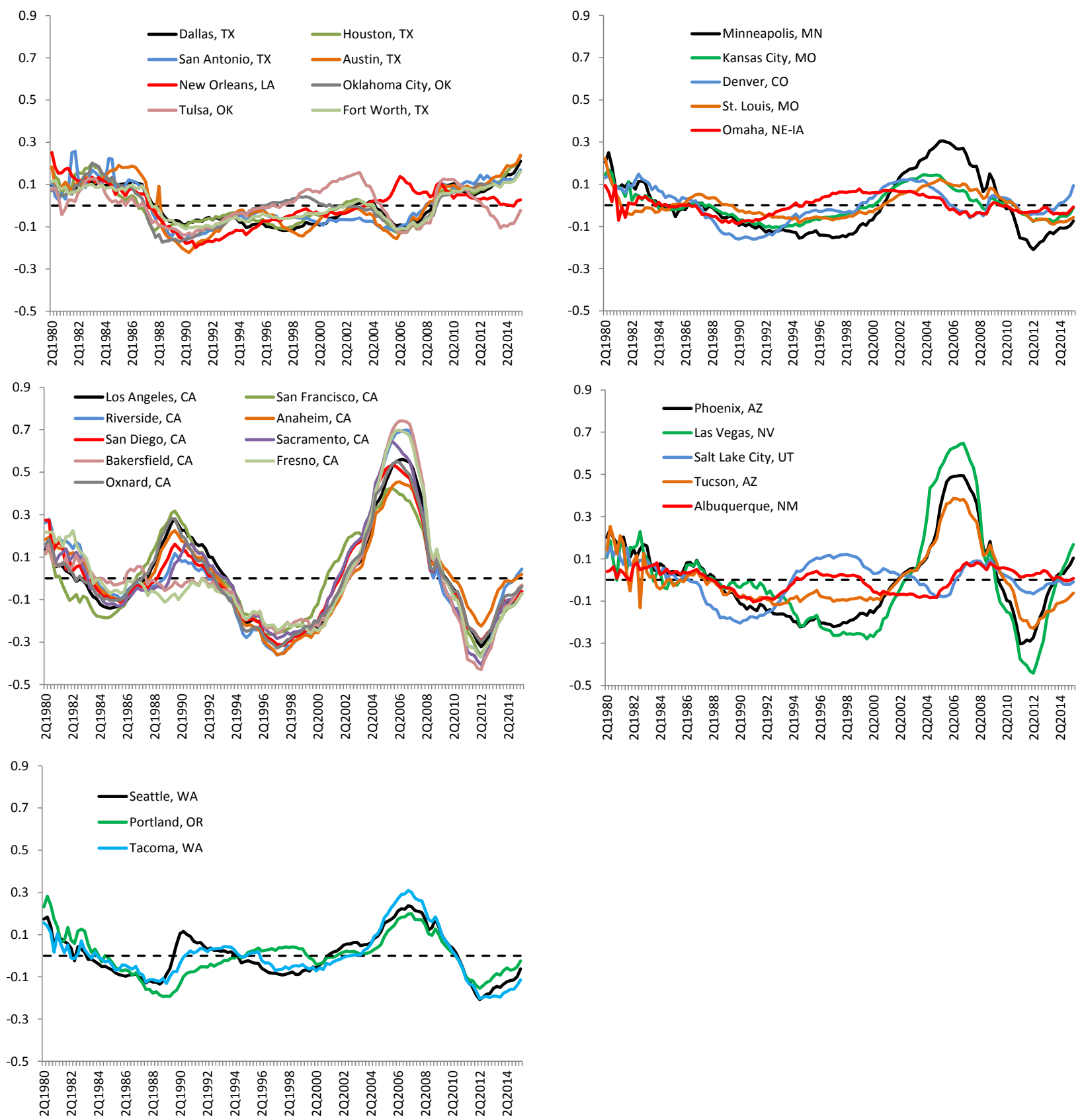
Figure 6. Geographic distribution of maximum price overshoots in the 2000s (IN COLOR)

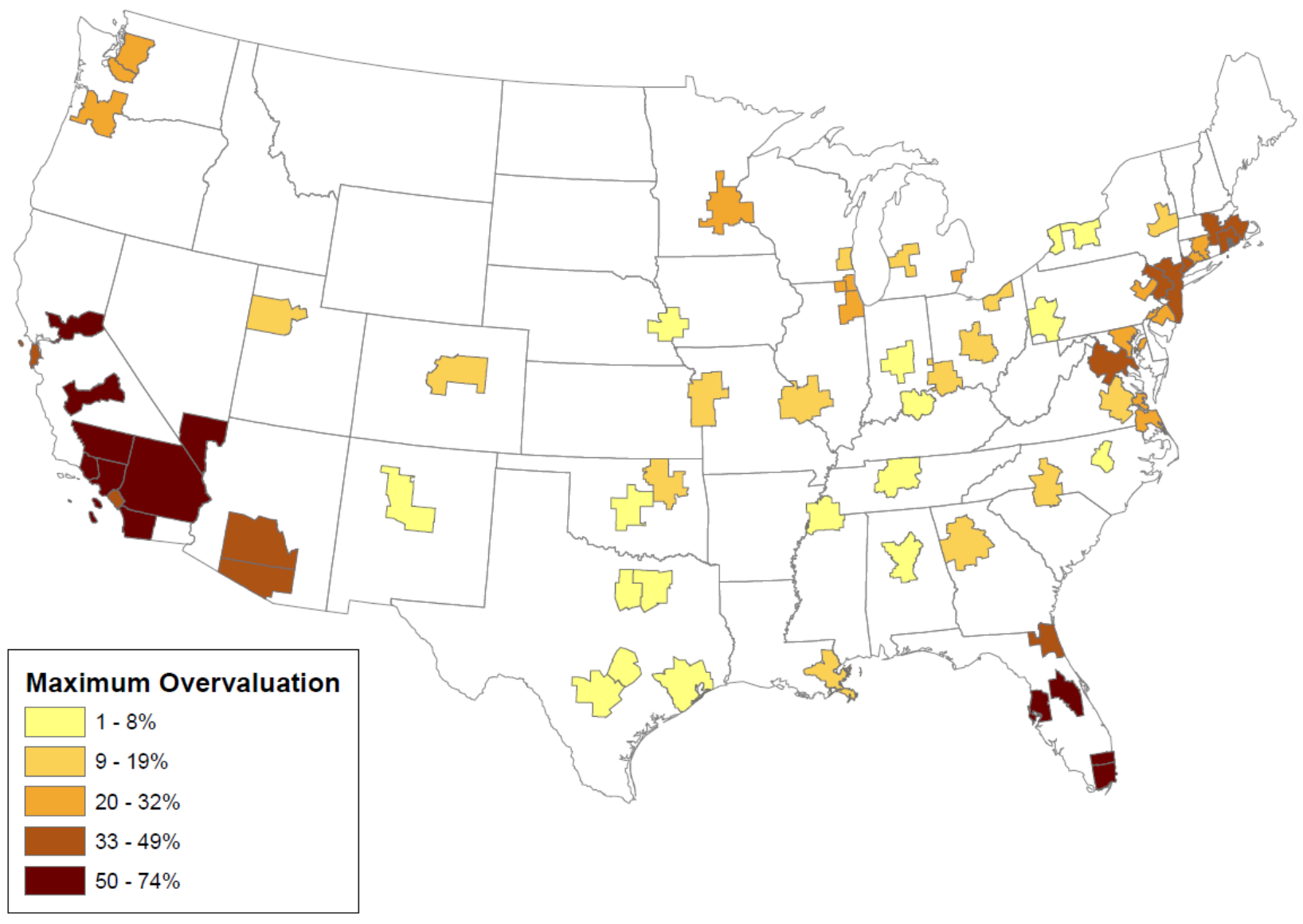


Figure 7. Relationship between the peak of price overshoot in the 2000s and price elasticity of housing supply

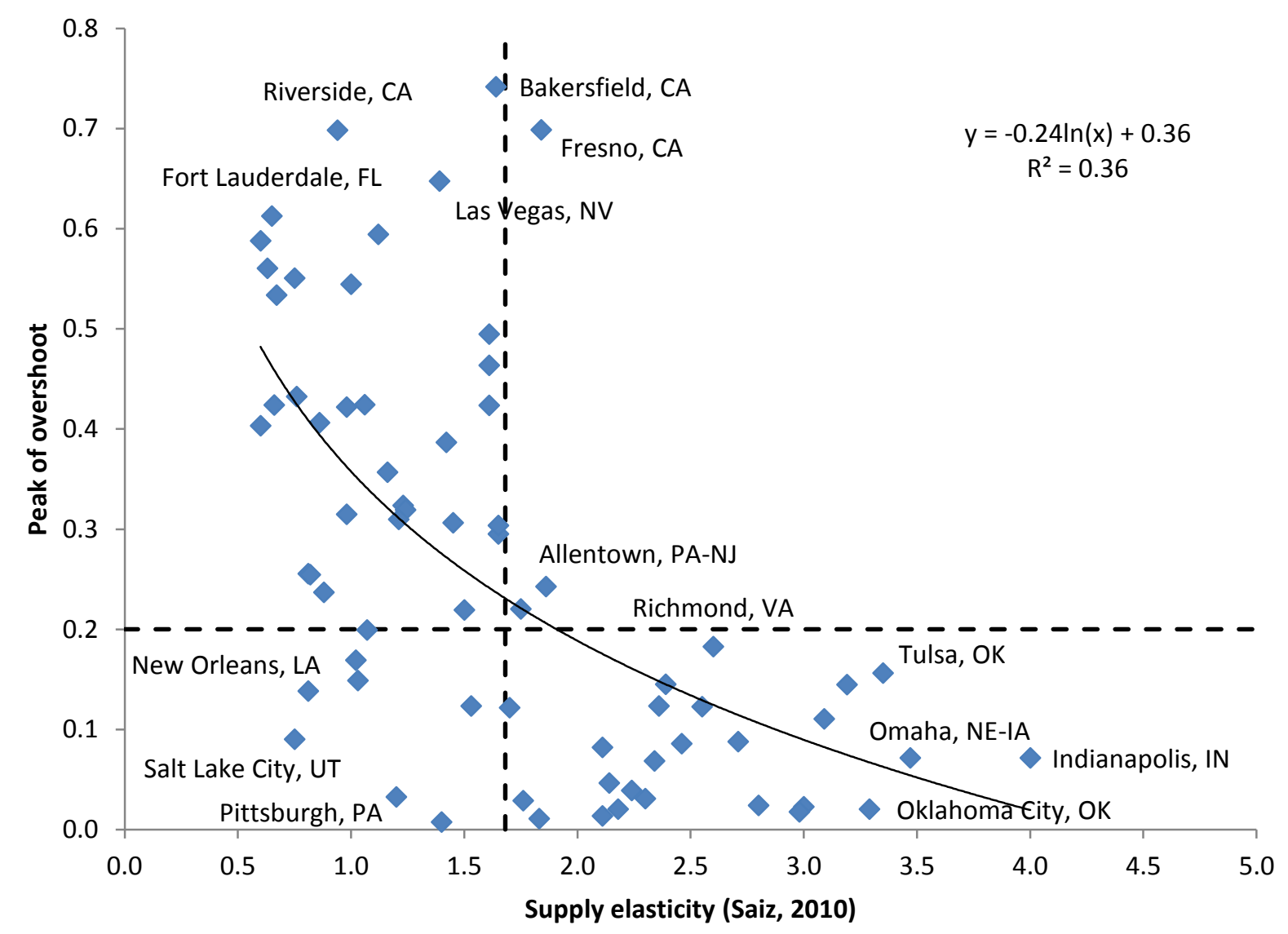


Figure 8. Cross-correlation between momentum and equilibrium-adjustment parameters

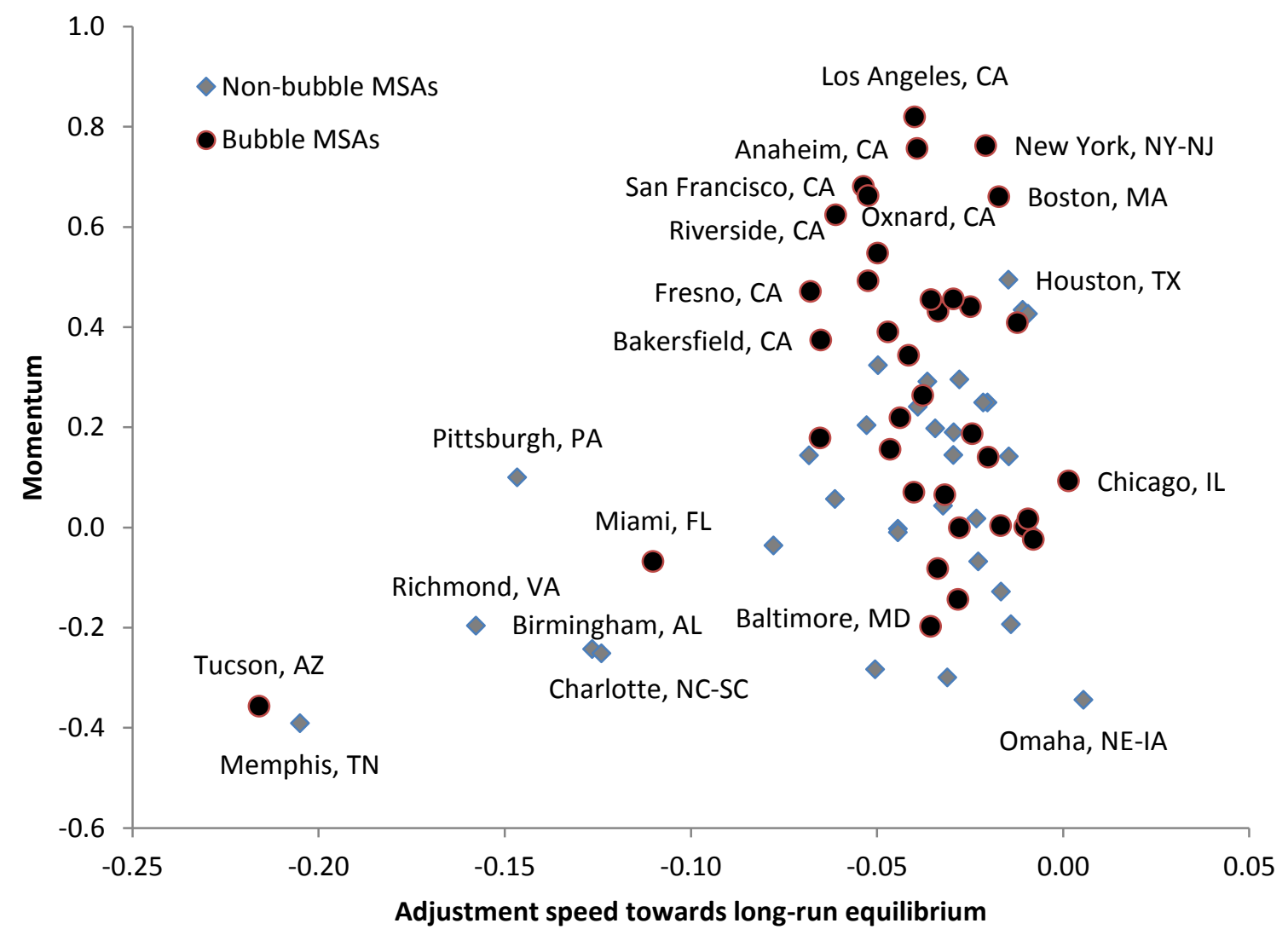

